\section{WORKING PAPER}

No. $38-09$

The Place of Nature in Economic Development
Partha Dasgupta

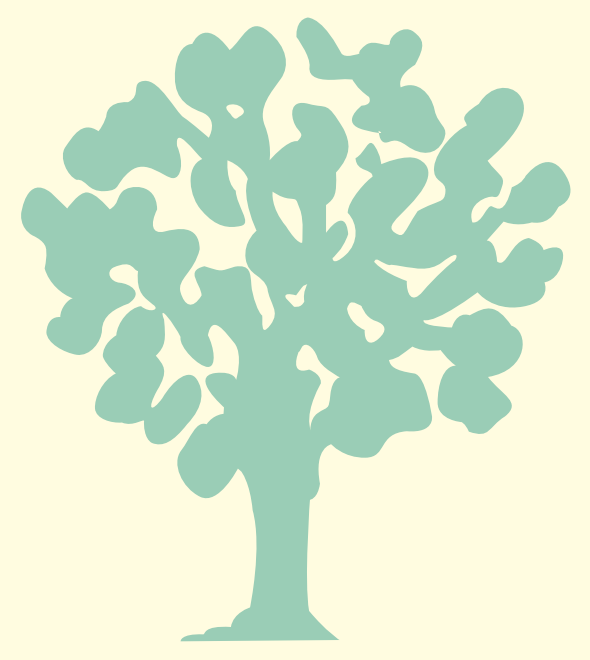




\title{
The Place of Nature in Economic Development
}

\author{
PARTHADASGUPTA
}

University of Cambridge and University of Manchester

London, UK

January 2009

South Asian Network for Development and Environmental Economics (SANDEE) PO Box 8975, EPC 1056

Kathmandu, Nepal 
Published by the South Asian Network for Development and Environmental Economics (SANDEE)

PO Box 8975, EPC 1056 Kathmandu, Nepal.

Telephone: 977-1-552 8761, 5526391 Fax: 977-1-553 6786

SANDEE research reports are the output of research projects supported by the South Asian Network for Development and Environmental Economics. The reports have been peer reviewed and edited. A summary of the findings of SANDEE reports are also available as SANDEE Policy Briefs.

National Library of Nepal Catalogue Service:

Partha Dasgupta

The Place of Nature in Economic Development

(SANDEE Working Papers, ISSN 1893-1891; 2009- WP 38)

ISBN: 978 - $9937-8093-5-1$

The views expressed in this publication are those of the author and do not necessarily represent those of the South Asian Network for Development and Environmental Economics or its sponsors unless otherwise stated. 


\section{The South Asian Network for Development and Environmental Economics}

The South Asian Network for Development and Environmental Economics (SANDEE) is a regional network that brings together analysts from different countries in South Asia to address environment-development problems. SANDEE's activities include research support, training, and information dissemination. SANDEE is supported by contributions from international donors and its members. Please see www.sandeeonline.org for further information about SANDEE.

This work was carried out with the aid of grants from several sponsors, including the International Development Research Center, Canada, the Swedish International Development Cooperation Agency and the Norwegian Agency for Development Cooperation. The views expressed in this publication are those of the author and do not represent the views of the South Asian Network for Development and Environmental Economics or its sponsors.

The author is the Frank Ramsey Professor of Economics at the University of Cambridge; Fellow of St John's College, Cambridge; and Professor of Environmental \& Development Economics at the University of Manchester. E-mail address: partha.dasgupta@econ.cam.ac.uk Prepared for the Handbook of Development Economics, Vol. 5, edited by Dani Rodrik and Mark Rosenzweig (Amsterdam: North Holland), 2009. 



\section{TABLE OF CONTENTS}

1. NATURAL CAPITAL AND ECONOMIC DEVELOPMENT 2

2. NATURAL CAPITALAND DEVELOPMENT ECONOMICS 4

$\begin{array}{ll}\text { 3. TYPES OF NATURAL CAPITAL } & 6\end{array}$

4. CONTENTS 8

4.1. EXTERNALITIES 8

5. UNIDIRECTIONAL EXTERNALITIES: EXPORTS ANDWEALTH

TRANSFERS 9

$\begin{array}{lll}5.1 & \text { QUANTIFYING EXTERNALITIES } & 10\end{array}$

5.2 INTERNALIZING EXTERNALITIES 11

6. RECIPROCAL EXTERNALITIES: COMMON PROPERTY

RESOURCES (CPRs) 12

$\begin{array}{lll}\text { 6.1 WHY CPRS? } & 13\end{array}$

6.2 THE IMPORTANCE OF CPRS 14

$\begin{array}{lll}6.3 & \text { THE GOOD NEWS ABOUT CPRS } & 14\end{array}$

6.4 THE BAD NEWS ABOUT CPRS 16

$\begin{array}{ll}6.5 & \text { VALUATION, EVALUATION, AND SUSTAINABLE } \\ \text { DEVELOPMENT } & 19\end{array}$

$\begin{array}{ll}\text { 7. INADEQUACIES IN GDP } & 20\end{array}$

8. VALUING GOODS AND SERVICES 21

$\begin{array}{lll}\text { 8.1 DEFINING SHADOW PRICES } & 21\end{array}$

8.2 ESTIMATING SHADOW PRICES 22

9. SOCIAL WELL-BEING AND COMPREHENSIVE WEALTH 25

$\begin{array}{lll}9.1 & \text { A UNIFYING MODEL } & 25\end{array}$

9.2 THE WELFARE SIGNIFICANCE OF NET DOMESTIC PRODUCT 27 
10. COMPREHENSIVE INVESTMENT AND SUSTAINABLE

10.1 THE BASIC THEORY 27

10.2 GLOBAL PUBLIC GOODS 29

10.3 ANAPPLICATION 30

11. EVALUATING POLICY REFORMS 32

11.1 SOCIAL COST-BENEFITANALYSIS 33

11.2 EVALUATING PROJECTS IN PRACTICE 34

12. DISCOUNTING CLIMATE CHANGE 37

12.1 GLOBAL ACTIVISM NOW OR LATER? 37

12.2 NEGATIVE DISCOUNT RATES 38

12.3 THE WELFARE ECONOMICS OF CLIMATE CHANGE 38

12.4 SOCIAL AVERSIONS TO INEQUALITY AND RISK 40

12.5 CLIMATE TREATIES 41

13. CONCLUSIONS 42

14. ACKNOWLEDGEMENTS 44

REFERENCES

$\begin{array}{ll}\text { APPENDIX } & 63\end{array}$

A.1 ECONOMIC PERTURBATION AS MOVEMENTTHROUGH TIME: SUSTAINABLE DEVELOPMENT 63

A.1.1 THE FORMAL ANALYSIS 63

A.1.2 ACCOUNTING FOR POPULATION GROWTH 65

A.2 POLICYEVALUATION 66

TABLE

TABLE 1: THE PROGRESS OF POOR NATIONS 68 




\title{
The Place of Nature in Economic Development
}

\author{
Partha Dasgupta
}

Are humanity's dealings with nature sustainable? Should one expect the global economic growth that has been experienced over the past five decades to continue in the foreseeable future? Should we be confident that knowledge and human skills will increase in such ways as to lessen our reliance on nature in relation to humanity's growing numbers and rising economic activity?

Contemporary discussions on these questions are now several decades old. If they have remained alive and continue to be shrill, it is because two opposing empirical perspectives shape them. On the one hand, if we look at specific examples of natural capital (aquifers, ocean fisheries, tropical forests, the atmosphere as a carbon sink - or ecosystems, generally), there is convincing evidence that at the rates at which we currently exploit them they are very likely to change character dramatically for the worse, with little advance notice. Indeed many ecosystems have already collapsed, with short notice. ${ }^{1}$ Hassan et al. (2005) and Carpenter et al. (2005), which contain the first two sets of technical reports accompanying the Millennium Ecosystem Assessment (M.E.A., 2003), found that some 15 out of the 24 major ecosystem services that were examined for the Assessment are either already degraded or currently subject to unsustainable use. On the other hand, if we study historical trends in the prices of marketed resources, or improvements in life expectancy, or growth in recorded incomes in regions that are currently rich and in those that are on the way to becoming rich, resource scarcities wouldn't appear to have bitten. Suppose you were to point to the troubled nations of sub-Saharan Africa and suggest that resource scarcities are acute there today. Those with the former perspective (ecologists generally) will tell you that it is because people in the world's poorest regions face acute resource scarcities relative to their numbers that they are so poor, while those with the latter perspective (economists usually) will inform you that people there experience serious resource scarcities because they are poor. When experts disagree over such a fundamental matter as the direction of causation, there is little to go on.

Those conflicting intuitions are also not unrelated to an intellectual tension between the concerns people share about carbon emissions and acid rains that sweep across regions, nations and continents, and about declines in firewood and water sources that are specific to the needs and concerns of the poor in small, village communities. That is why "environmental problems" present themselves in different ways to different people. Some identify environmental problems with population growth, while others identify them with wrong sorts of economic growth. Then there are those who view them through the spectacle of poverty. Each of those visions is correct. There is no single environmental problem; there is a large collection of them (Ehrlich and Ehrlich, 1981, 1990; Dasgupta, 1993, 2001a; Sachs, 2008).

Growth in industrial and agricultural pollutants has accompanied economic development; and in industrialized countries neither preventive nor curative measures have kept pace with their production. That neglect is now prominent in the rapidly growing regions in China, India, Mexico,

\footnotetext{
An "ecosystem" is a complex of the a-biotic environment and plant, animal, fungi, and microorganism communities, interacting as a functional unit. Humans are an integral part of ecosystems. M.E.A. (2003) Hassan et al. (2005), Reid et al. (2005), and Brauman et al. (2007) offer excellent accounts of the role ecosystems play in economic life.
} 
and Brazil. Moreover, the scale of the human enterprise, both by virtue of unprecedented increases in the size of the world's population and the level of economic activity, has so stretched the capabilities of ecosystems, that humankind is today Earth's dominant species. During the 20th century world population grew by a factor of four (to more than 6 billion) and world output by 14 , industrial output increased by a multiple of 40 and the use of energy by 16 , methane-producing cattle population grew in pace with human population, fish catch increased by a multiple of 35, and carbon and sulphur dioxide emissions by more than 10 . The application of nitrogen to the terrestrial environment from the use of fertilizers, fossil fuels, and leguminous crops is now at least as great as that from all natural sources combined. In a notable work Vitousek et al. (1986) estimated that $40 \%$ of the $45-60$ billion metric tons of carbon that are harnessed annually by terrestrial photosynthesis (net primary production of the biosphere) is currently being appropriated for human use. To be sure, this is a rough estimate; still, the figure puts the scale of the human presence on the planet in perspective (see also Vitousek et al., 1997; Daily and Ellison, 2002; M.E.A., 2003; Hassan et al., 2005; Carpenter et al., 2005; Ehrlich and Ehrlich, 2008).

On the other hand, economic growth itself has brought with it improvements in the quality of a number of environmental resources. The large-scale availability of potable water and the increased protection of human populations against both water- and air-borne diseases in industrial countries have come with the economic growth those countries have enjoyed over the past 200 years. Moreover, the physical environment inside the home has improved beyond measure. Cooking in South Asia continues to be a central cause of respiratory illnesses among women. Growth in scientific knowledge, investment in public infrastructure, and universal education in advanced industrial countries have meant that citizens there have far greater knowledge of environmental hazards than their counterparts in poor regions and have the resources to avoid them. Such positive links between economic growth and environmental quality often go unacknowledged by environmentalists in the West.

\section{Natural Capital and Economic Development}

Despite the conflicting intuitions, most economists would appear to be convinced that technological advances and the accumulation of reproducible capital and growth in human capital can overcome diminutions in natural capital. Otherwise it is hard to explain why twentieth-century economics has been so detached from the environmental sciences. Judging by the profession's writings, we economists see nature, when we see it at all, as a backdrop from which resources and services can be drawn in isolation. Macroeconomic forecasts routinely exclude natural capital, and accounting for nature, if it comes into the calculus at all, is an afterthought to the real business of "doing economics". When asked, economists acknowledge nature's existence, but many deny she is worth much. I have heard professional colleagues remark at seminars that the services nature provides amount at best to 2-3\% of an economy's output, which is the share of agriculture in the gross domestic product (GDP) of the United States. Why, they ask, should one incorporate a capital asset of negligible importance in macro-economic models of growth and distribution?

Typically it is assumed in growth models that nature is a fixed, indestructible factor of production (Ricardo's "land"). ${ }^{2}$ The problem with the assumption is that it is wrong: nature consists of degradable resources. Agricultural land, forests, watersheds, fisheries, fresh water sources,

Barro and Sala-i-Martin (2003), Helpman (2004), and the survey articles in Aghion and Durlauf (2005) provide excellent examples. 
estuaries, the atmosphere - more generally, ecosystems - are resource stocks that are selfregenerative, but suffer from depletion or deterioration when they are over-used. (I am excluding oil and natural gas, which are at the limiting end of self-regenerative resources.) Moreover, the environmental sciences tell us that the elasticity of substitution between reproducible capital and human capital, on the one hand, and vital forms of natural capital, on the other, are less than one (Ehrlich and Goulder, 2007). It may have been understandable of economists to assume that nature doesn't need to be counted at a time when natural resources were abundant relative to the demand that was made of them, but it isn't understandable in models of development possibilities open to the world today. The stance taken in modern growth models is questionable also because property rights to natural capital are often either vaguely defined or weakly enforced (Sections 5-6), implying that nature's services are underpriced in the market. Official statistics on national income certainly give the impression that natural capital is of small importance; but official statistics are built on market prices, not shadow prices. Studies of local ecosystems suggest that if shadow prices were to be used in economic statistics, the decomposition of national income into its various components would look quite different. For example, Repetto et al. (1989) and Vincent et al. (1997) estimated the decline in forest cover in Indonesia and Malaysia, respectively, and found that when depreciation is included, national accounts there look quite different: net saving rates are some $20-30 \%$ lower than recorded rates. In their work on the depreciation of natural resources in Costa Rica, Solorzano et al. (1991) found that the depreciation of three resources (forests, soil, and fisheries) amounted to about 10\% of GDP and over a third of capital accumulation.

Distortions in the pricing of primary factors of production filter down to influence research and development. The latter in turn influences the character of technological change. Because nature's services are underpriced in the market, innovators have little reason to economize on their use. We shouldn't be surprised when new technologies are rapacious in the use of natural capital.

Modern growth theories ignore every layer of those resource allocation failures. Recent concerns over global climate change and the growing scarcity of fresh water in the world's poorest regions are perhaps the first acknowledgement among mainstream development economists and international development agencies (e.g., Stern, 2006; UNDP, 2006, 2007/08) that at the scales at which the world economy has been operating for some time, nature is in many aspects fragile.

In any case we should be sceptical of a theory of economic progress that places such enormous burden on an experience not much more than 250 years old. Extrapolation into the past is a sobering exercise: over the long haul of history (a 5000 years stretch, say, up-to about 250 years ago), economic growth even in the currently-rich regions was for most of the time not much above zero. The study of possible feedback loops between poverty, population growth, and the character and performance of both human institutions and natural capital is not common currency in modern growth models. Which is probably why environmental- and resource-economics, or ecological economics for short, remains isolated from the main body of contemporary economic thinking.

Evidence of that isolation has been provided strikingly, even if unintentionally, by Kim et al. (2006), who identified what has mattered to the economics profession since 1970, by surveying 41 of the most prominent refereed economics journals. In his Plenary Lecture in 2007 at the 
Annual Conference of the European Association of Environmental and Resource Economists, Ehrlich (2008: p.16) observed that the following words appeared neither in Kim et al. (2006), nor in the titles of the top 146 articles (500 cites or more) in those 41 journals: "abatement, aquifer, ..., biotic, ..., carrying capacity, climate, ..., ecosystem, ..., fertility, forest, ..., pollution, population, poverty, ..., soil, ..., toxic, ..., warming, and water."

\section{Natural Capital and Development Economics}

Official development economics reflects the rest of our discipline, in that it too neglects nature's place in economic development. The neglect looks odd to ecologists, who are trained to study the slow processes that influence long-term development possibilities. A seemingly natural retort to ecologists is that people come first and that, after all, current poverty should matter most. There are two problems with the position. First, the future has a habit of becoming the present. Secondly, extreme poverty is frequently associated with a degraded environment.

It could be that economists neglect nature because the services it provides are judged to be luxury goods, as in the view expressed in prominent newspapers that "economic growth is good for the environment because countries need to put poverty behind them in order to care," (The Independent, 4 December 1999), or that "... trade improves the environment, because it raises incomes, and the richer people are, the more willing they are to devote resources to cleaning up their living space," (The Economist, 4 December, 1999). But in the poor world natural capital is not only an amenity, it is also a primary factor of production. Often it's a basic need (see World Resources Institute, 2005, for a global summary). In an early publication, Falconer (1990) recorded the major significance of "minor" forest products among the poor in the humid forest zone of West Africa. She also recorded the many different ways people there have coped with a decline in their access to those products. Perrings (2000) is an exceptional study of the role that biodiversity plays in the lives of the poor in agro-pastoral sub-Saharan Africa. The author also records the decline in biodiversity in recent decades and looks for its causes. In a carefully designed study in the rainforest of Chiapas, Mexico, Lopez-Feldman and Wilen (2008) found that non-timber products there are extracted mainly by the poor. They attribute that in part to the fact that extraction involves search and that the opportunity cost of time (relative to the value of non-timber products to the extractor) is low among the poor.

Hassan et al. (2005) is the most comprehensive study to date on the state of the local naturalresource base in poor regions. The studies confirm that the world's poorest people (some 620 million in number) live in especially fragile natural environments. When wetlands, inland and coastal fisheries, woodlands, forests, estuaries, village ponds, aquifers, and grazing fields are damaged (owing to agricultural encroachment, nitrogen overload, urban extensions, the construction of large dams, resource usurpation by the state, open access, or whatever), it is the rural poor who suffer most. Frequently, there are no alternative sources of livelihood. In contrast, for rich eco-tourists or importers of primary products, there is something else, often somewhere else; which means that there are alternatives.

There may be a second reason why economists have neglected natural capital. Public concerns over environmental problems are often prompted by large-scale disasters, such as nuclear leakage, storms, and floods. The environmental impacts of large undertakings (big dams and irrigation systems) also catch the public eye. This shouldn't surprise. Big impacts of "single" incidents are directly visible. So they provoke public outcry and elicit a response. In contrast, the slow, shifting 
processes that characterize human-nature interactions aren't easy to detect by outsiders; at least, not unless and until a threshold is reached and a catastrophe occurs. Of course, in the poor world small-scale disasters occur all the time, it's only that they aren't visible to outsiders. But large numbers of small-scale disasters can over time add up to greater human losses than a small number of large-scale catastrophes. Empirical evidence collected over the past two decades confirms an earlier intuition that rural poverty and environmental degradation in poor countries is in large measure caused by those institutional failures whose deleterious effects accumulate slowly over time (Dasgupta, 1982; Repetto, 1988; Hassan et al., 2005).

Up-to now, even growth in the atmospheric concentration of carbon dioxide has affected economic outcomes very slowly. But as the evidence suggests, the process characterising global climate change is remorseless and in all probability harbours any number of tipping points for the future (Lenton et al., 2008). Although international development agencies (e.g., UNDP, 2007/8) are now acknowledging the costs that people in the tropics are likely to face owing to climate change, their concerns have been largely about the efficacy of an international "cap-and-trade" system and the assistance rich nations ought to give poor countries in order to meet climate change. They are legitimate concerns, but it seems to me in order to identify good policies one needs to examine the pathways by which people may get trapped in poverty when development prescriptions ignore natural capital. That requires analysis, not rhetoric.

The systematic neglect of ecology in development economics should be puzzling. 65-75\% of people in the world's poorest regions live in rural areas. Mention agricultural land, threshing grounds, grazing fields, village tanks and ponds, woodlands and forests, rivers and streams, coastal fisheries, mangroves, or coral reefs, and the importance of the local natural-resource base to the rural poor becomes self-evident. In a pioneering study, the (Indian) Centre for Science and Environment (C.S.E., 1990) recorded that, of the total number of hours worked by villagers in a micro-watershed in the central Himalayas in India, 30\% was devoted to cultivation, 20\% to fodder collection, and about $25 \%$ was spread evenly between fuel collection, animal care, and grazing. Some $20 \%$ of time was spent on household chores, of which cooking took up the greatest portion, and the remaining 5\% was involved in other activities, such as marketing.

Subsequent studies (e.g., Filmer and Pritchett, 2002) have also recorded the importance of the local natural-resource base in rural life. Nevertheless, apart from agricultural land, ecological capital has been absent from the formal models mainstream development economists have used to discuss policy. It is absent too from influential surveys and texts on the economics of development (Stern 1989; Dreze and Sen, 1990, 1995; Ray, 1998; Sen, 1999; Banerjee and Duflo, 2005).

That neglect has had far-reaching implications for development policy. Tallis et al. (2008) report that of the more than 11,000 development projects that have been supported by the World Bank since 1947, only about 15\% have included natural capital as a theme. They also report that the number of World Bank projects approved in the period 1993-2007 that had biodiversity as a theme and poverty alleviation and the protection of ecological capital as stated goals was a mere 32, and that only five of those recorded improvements in environmental quality and a reduction in poverty. As all economies suffer from serious distortions in the use of ecological capital (see below), it should be possible to identify policy reforms that both help to reduce poverty and improve ecological services (Repetto et al., 1992). With that in mind, Tallis et al. (2008) have compiled a list of indicators that should prove useful in designing, selecting, and implementing projects that offer the prospect of reaching what the World Bank calls "win-win outcomes". 
Despite the neglect, there is now a growing literature on the links between rural poverty and the local ecology. Because economic theory predated economic empirics in that body of work, empirical studies have frequently been designed by scholars to respond to the theory. In this paper I draw on that literature to show how economics can be reworked to include nature's services in the study of development processes. ${ }^{3}$ Unfortunately, even now there are few reliable empirical studies. One reason for the dearth may be that, with the exception of forest cover, government surveys (even the best of them, such as the Indian National Sample Survey) don't include detailed information on ecological capital. In addition to studying household behaviour, investigators therefore have to obtain their own data on the state of the local ecology.

Even though the field is nascent, the literature I report below stands somewhat in contrast to the environmental and resource economics that was developed over the decades in the United States. In part influenced by the needs of the US Environmental Protection Agency (EPA), resource economists there mostly studied the economics of timber, oil and natural gas, water resources, and fisheries; while environmental economists focussed on environmental amenities and pollution. Moreover, it was customary in the earlier literature to interpret environmental problems as symptoms of market failure. ${ }^{4}$

I shall put some distance between the material I report in this paper and the themes usually covered in environmental and resource economics. I shall do that partly because, in identifying the place of natural capital in the lives of the rural poor, I want to shift the focus onto ecological services; but partly also because in poor countries, people transact in a wide variety of nonmarket institutions. It will be seen below that the inclusion of natural capital in economic reasoning alters not only our assessment of the contemporary development experience, but our understanding of development processes as well. So as to emphasize that the context I am studying here is rural poverty, we will regard ecological capital to be the quintessential example of natural capital. When necessary, though, I shall allude to natural capital, interpreted in an inclusive way. ${ }^{5}$

\section{Types of Natural Capital}

Natural capital is of direct use in consumption (fisheries); of indirect use, as inputs in production (timber); or of use in both (fresh water). The value of a resource is often derived from its usefulness (as a source of food, or as an essential actor in ecosystems - e.g., a keystone species); but there are resources whose value is aesthetic (places of scenic beauty), or intrinsic (primates, blue whales, sacred groves), or a combination of all three (biodiversity). The worth of a natural resource could be based on what is extracted from it (forest products, fisheries), or on its presence as a stock offering service (coral reefs, wetlands, forest cover), or on both (watersheds).

3 For many years now I have both grumbled about the continual neglect of the natural-resource base in the study of poverty in poor countries and tried to bring together environmental and development economics (Dasgupta 1982, 1990, 1993, 2001a, 2003, 2004, 2008a,b; Dasgupta and Mäler, 1991). Since its inception in 1996, the journal Environment and Development Economics has done much to advance the subject.

4 Scholars at Resources for the Future have been prominent in developing that excellent body of work. Kneese and Schultze (1975) is a fine representative. Kolstad (2007) and Siebert (2008) are excellent texts on the subject, covering both theory and optimal policy.

5 The publications that drew attention to the economic importance of ecosystems are the classics by Ehrlich et al. (1977) and Daily (1997). Hassan et al. (2005) and Brauman et al. (2007) provide a catalogue of those services. For a succinct account of policy measures that are currently being taken across the world with ecological services as the focus, see Turner and Daily (2008). 
Ecosystems provide innumerable services to us. Among the visible products are food, fibres, fuel, and fresh water, but many remain hidden from view. Among other things, ecosystems maintain a genetic library, preserve and regenerate soil, fix nitrogen and carbon, recycle nutrients, control floods, mitigate droughts, filter pollutants, assimilate waste, pollinate crops, operate the hydrological cycle, and maintain the gaseous composition of the atmosphere. As those services are not visible, it is easy to overlook them. However, with some ingenuity it is possible to estimate the benefits we enjoy from them. Below I report some of those findings.

Ecosystems offer joint products: wetlands recycle nutrients and produce purified water; mangrove forests protect coastal land from storms and are spawning grounds for fish; and so on. Unhappily, social tensions arise in those many cases where an ecosystem has competing uses (farms versus forests versus urban developments; forests versus agro-ecosystems; coastal fisheries versus aquaculture ${ }^{6}$ ). As natural capital is a mesh of resources, what one means by an ecosystem is usually influenced by the scope of the problem being studied. A number of ecosystems have a near global reach ("biomes", such as the Savannah), some cover entire regions (river basins), many involve clusters of villages (micro-watersheds), while others are confined to the level of a single village (the village pond). Sachs et al. (1998) have traced the location of world poverty in part to the fact that the tropics harbour some of the most fragile environments. Hassan et al. (2005) and Carpenter et al. (2005) contain a classification of ecosystems. They also provide an account of the stresses that are being experienced by both global and local ecosystems.

Environmental pollutants are the reverse of natural resources. In some cases the emission of pollutants amounts directly to the depreciation of reproducible capital (corrosion of material infrastructure). In others it means a degradation of ecosystems (eutrophication of lakes). Roughly speaking "resources" are "goods", many being sinks into which pollutants are discharged (rivers, the atmosphere, and the oceans are among the sinks); while "pollutants" (the degrader of resources) are "bads". Pollution is the other side of conservation. ${ }^{7}$

Ecosystems are driven by interlocking non-linear processes that run at different speeds and operate at various spatial scales (Steffen et al., 2004). That is why ecosystems harbour multiple basins of attraction. The global climate system is now a well known example (Bigg, 2003). But small-scale ecosystems also harbour multiple basins of attraction, for similar reasons. So long as phosphorus run-off into a fresh water lake is less than the rate at which the nutrient settles at the bottom, the water column remains clear. But if over a period of time the run-off exceeds that rate, the lake collapses into a eutrophic state. ${ }^{8}$ Usually, of course, the point at which the lake will collapse is unknown. That means the system is driven by non-linear stochastic processes. So, flips in the capacity of ecosystems to supply useful service to us share three important characteristics: (1) they are frequently irreversible (or at best they take a long time to recover); (2) except in a very limited sense, it isn't possible to replace degraded ecosystems by new ones; and (3) ecosystems can collapse abruptly, without much prior warning. Imagine what would happen to a

\footnotetext{
See Tomich et al., eds. (2004); Tomich et al. (2004) and Palm et al. (2005); and Hassan et al. (2005), respectively, on those tensions.

This classification was explored in Dasgupta (1982).

8 See Carpenter et al. (1999) and Carpenter (2001) for an analysis of the dynamics of (shallow) fresh-water lake systems. The existence of multiple basins of attraction has important implications for the way the lake's shadow price ought to be estimated. Dasgupta and Mäler (2003) is a collection of essays that develops the welfare economics of non-linear ecosystems (see, for example, the article by Brock and Starrett, 2003).
} 
city's inhabitants if the infrastructure connecting it to the outside world was to break down without notice. Vanishing water sources, deteriorating grazing fields, barren slopes, wasting mangroves, and bleached coral reefs are spatially confined instances of a corresponding breakdown among the rural poor. Ecological collapse, such as the one that has been experienced in recent years in Rwanda, the Horn of Africa, and the Darfur region of Sudan, can also trigger rapid socioeconomic decline (Homer-Dixon, 1999; Diamond, 2005; Collier, 2007).

\section{Contents}

The plan of this paper is as follows:

In Sections 5-6, I introduce two broad categories of externalities and discuss the kinds of institutions that are likely to be most effective in removing them. The remainder of the paper discusses ways to value natural capital and develops a method for evaluating economic programmes. Two types of evaluation exercises are contrasted: evaluating projects and identifying sustainable development. In Section 7, I show that GDP should not be used as a welfare index in either exercise. Section 8, contains a discussion of a number of methods for valuing ecological capital. In Section 9, I show that a comprehensive measure of wealth is the correct index to use in both types of evaluation exercise. Section 10, demonstrates the reach of the index for identifying sustainable development. Section 11, does the same for project evaluation.

In many people's minds today, "environmental problems" mean "climate change". One of my aims in this paper is to dispel that notion. Nevertheless, in the long run climate change would appear to be one of the most serious environment problems facing poor countries. So in Section 12, I offer an extended discussion of those evaluation methodologies that have fashioned the empirical work on the economics of climate change. I point to weaknesses in the analyses, rather than harp on their strengths. Section 13 summarizes; and the Appendix has a formal demonstration of the theoretical propositions put forward in Sections 9-11.

Throughout, I try to mingle theoretical analysis with empirical studies. I do that not only for micro studies (e.g., the value of planting farm forests and investing in fresh water sources; measuring the value of upland forests in stabilizing water flows downstream), but also for macroeconomic identification of sustainable development. I do the latter by putting the theory to work on interpreting the development experience of the world's poorest regions in the period 1970-2000. With regard to the former, it is as well to note that empirical studies of household and village behaviour governing local ecosystems differ widely in style. They range from narratives on the lives of people in a single village to econometric studies of data from many villages. Even among the latter, some are based on carefully constructed controls, while others are more casual in their approach to statistics. I believe I have learnt from each of that heterogeneous body of styles. In any event, empirical studies of human-nature interactions are still so few in number, that it would be foolish to insist on the style we economists have got used to in applied micro-econometrics. The catholicity of styles will not suit everyone, but in drawing attention to it here I am merely placing my cards on the proverbial table.

\subsection{Externalities}

An early literature found market failure to be the underlying cause of environmental problems (Pigou, 1920; Meade, 1973; Baumol and Oates, 1975), which is why the phenomenon of market 
externalities looms large in environmental and resource economics. But there are non-market institutions too, and they also can fail. By an externality we mean the effects that decisions have on people who haven't been party to the decisions. I offer this definition because both theory and contemporary evidence tell us that environmental externalities are a symptom of a more general problem: institutional failure. The malfunctioning institution could be the market. But the failure could be that of a group of nations unable to agree on common fisheries policy in the seas; or it could be the state riding roughshod over forest inhabitants; it could be the local community whose norms have collapsed (Section 6); or it could be the household, where the dominant male insists on growing fruit trees (because the fruit can be sold in the market to which the female doesn't have easy access) rather than trees that would supply the wood-fuel the female is expected to gather from the receding woodlands. The consequences of those malfunctions are resource allocation failures among contemporaries and across the generations. I shall also argue that one of the consequences has been the very high population growth the poor world has experienced in recent decades.

Activities involving ecological capital give rise to externalities because property rights to them are either weakly defined or inadequately enforced. And a common reason for the latter is that key components of natural capital are mobile, as is the case with air and water. By property rights I don't only mean "private" property rights, I include "community" property rights and state property rights. At an extreme end are "global" property rights on global public goods, a concept that is implicit in current discussions on climate change. But neither the idea of global property rights nor of global public goods is new. That humanity has collective responsibility over the state of the world's oceans used to be explicit in the 1970s, when politicians claimed that the oceans are a "common heritage of mankind".

In the presence of externalities involving nature's services, individuals and communities overexploit natural capital, which is another way of saying that ecological services are subsidized. At the global level what is the annual subsidy? One calculation suggested that it is $10 \%$ of annual global income (Myers and Kent, 2000). My reading is that the margin of error in that estimate is very large. But it's the only global estimate I have come across. The technical reports accompanying M.E.A. (2003), especially Hassan et al. (2005) and Carpenter et al. (2005) contain quantitative information that could be used to obtain more reliable estimates of nature's subsidies; which in turn could be used to estimate the shadow prices of various ecological capital assets (Section 8). International organizations such as the World Bank have the resources to undertake that work. But they appear to be reluctant to do so.

Two broad types of externalities may be contrasted: unidirectional and reciprocal (Dasgupta, 1982). Unidirectional externalities are just that - unidirectional - where one agent (or a set of agents) inflicts or confers an externality on another (or others). The direction of the externality is in part determined by social norms and legal rules (Coase, 1960), a matter to which I return below. Under reciprocal externalities each party inflicts or confers an externality on all others, as in the case of unmanaged common property resources. In the following two sections we study the significance of the two types of externalities.

\section{Unidirectional Externalities: Exports and Wealth Transfers}

Exports of primary products often involve unidirectional externalities. There is evidence that, other things being equal, freeing exports from politically motivated restrictions helps economies 
to grow faster. There is evidence too that the poor as a group enjoy the benefits of faster growth (McCulloch et al., 2001). But as the ecological consequences of growth in exports are rarely measured, the case for trade expansion should be qualified beyond the occasional footnote. Here is an example of how an increase in the export of primary products can hurt the poor. ${ }^{9}$

An easy way for domestic governments to earn revenue in countries that are rich in forests is to issue timber concessions to private firms. Imagine that concessions are awarded in the upland forests of a watershed. Forests stabilize both soil and water flow. So deforestation gives rise to soil erosion and increases fluctuations in water supply downstream. If the law recognizes the rights of those who suffer damage from deforestation, the timber firm would be required to compensate downstream farmers. But compensation is unlikely when (a) the cause of damage is many miles away, (b) the concession has been awarded by the state, ${ }^{10}$ and (c) the victims are scattered groups of farmers. Problems are compounded because damages are not uniform across farms: location matters. It can also be that those who are harmed by deforestation don't know the underlying cause of their deteriorating circumstances. As the timber firm isn't required to compensate farmers, its operating cost is less than the social cost of deforestation, the latter, as a first approximation, being the firm's logging costs and the damage suffered by all who are adversely affected. So, the export contains an implicit subsidy, paid for by people downstream. And I haven't included forest inhabitants, who now live under even more straightened circumstances; or worse, are evicted without compensation. The subsidy is hidden from public scrutiny, but it amounts to a transfer of wealth from the exporting to the importing country. Some of the poorest people in a poor country subsidize the incomes of the average importer in what could well be a rich country. That doesn't feel right.

\subsection{Quantifying Externalities}

The spatial character of unidirectional externalities is self-evident, but getting a quantitative feel involves hard work. So the literature is sparse. As in other fields of ecology and economics, some of the best advances in ecological economics have been made in studies of "small" problems. There are now several believable estimates of subsidies on the use of natural capital at the local level. Basing their estimate on a formal hydrological model, Pattanayak and Kramer (2001) reported that the drought mitigation benefits farmers enjoy from upstream forests in a group of Indonesian watersheds are 1-10\% of average agricultural incomes. In another exemplary work, Pattanayak and Butry (2005) studied the extent to which upstream forests stabilize soil and water flow in Flores, Indonesia (see also Pattanayak, 2004). Downstream benefits were found to be $2-3 \%$ of average agricultural incomes. In a study in Costa Rica on pollination services, Ricketts et al. (2004) discovered that forest-based pollinators increase the annual yield in nearby

$9 \quad$ The example is taken from Dasgupta (1990) and Chichilnisky (1994).

In a study of agricultural production in Ghana, Lopez (1997) found that under a common property regime (Section 6), biomass was exploited beyond the level at which aggregate profits would be maximized, implying that reciprocal externalities were at work. The author noted that the underlying externalities would be exacerbated if trade expanded. For further weaknesses of trade expansion under the contemporary world order, see Stiglitz (2002).

Trade doesn't invariably exacerbate negative externalities. An expansion in international trade in activities with negative externalities for which a country has a comparative disadvantage will reduce the externalities. I am grateful to Dani Rodrik for this observation.

10 Colchester (1995) has recounted that political representatives of forest-dwellers in Sarawak, Malaysia, have routinely given logging licenses to members of the state legislature. 
coffee plantations by as much as $20 \%$. Ricketts et al. (2008) have analysed the results of some two dozen studies, involving 16 crops in five continents, and discovered that the density of pollinators and the rate at which a site is visited by them declines at rapid exponential rates with the site's distance from the pollinators' habitat. At $0.6 \mathrm{~km}$ (resp. $1.5 \mathrm{~km}$ ) from the pollinators' habitat, for example, the visitation rate (resp. pollinator density) drops to $50 \%$ of its maximum. ${ }^{11}$

\subsection{Internalizing Externalities}

How should societies eliminate unidirectional externalities? In the case of the upstream firm and downstream farmers, the state could tax the firm for felling trees (Pigou, 1920). The firm in this case would be the "polluter", the farmers the "pollutees". Pigovian taxes therefore invoke the polluter-pays-principle (PPP). The efficient rate of taxation would be the damage suffered by farmers. What the state does with the tax revenue is a distributional matter, to which I shall return presently. Pollution taxes are known today as "green taxes".

But there is also a "market-friendly" way to eliminate externalities. Lindahl (1958 (1919)) - and subsequently Meade $(1953,1972)$ and Coase (1960) - suggested that the state (or the community; see Section 6) could introduce private property rights on ecological capital, the thought being that markets would emerge to eliminate the externalities. A problem with the proposal, at least as I have presented it here, is that it isn't clear who should be awarded property rights. In our example of the upstream firm and downstream farmers, the sense of natural justice might suggest that the rights should be assigned to farmers, who can be regarded as the pollutees. Under a system of "pollutees'-rights", the timber firm would be required to compensate farmers for the damage it inflicts on them. Such a property-rights regime also invokes PPP.

Of course, the rights could be awarded to the timber firm instead. In that case it would be the farmers who would have to compensate the firm for not felling trees. The latter system of property rights invokes the pollutee-pays-principle (a reverse PPP, as it were), which to many people would seem repellent. But from the efficiency point of view it's a matter of indifference which system of private property rights is introduced, so long, that is, as the prices that emerge (including those in the markets for externalities) are competitive prices (Starrett, 1972).

In a famous article Arrow (1971) pointed to a problem with Lindahl's proposal. Markets for externalities would be "thin". In our example each market would involve precisely two parties: the timber firm and one farmer. It is hard to imagine that competitive prices could emerge in such circumstances. Nevertheless, markets for externalities have attracted much attention among ecologists and development experts in recent years, under the label payment for ecosystem services, or PES (see Pagiola et al., 2005, for a sympathetic review of a market based PES).

The ethics underlying PES is seemingly attractive. If decision makers in Brazil believe that decimating the Amazon forests is the true path to economic progress there, shouldn't the rest of the world pay Brazil not to raze them to the ground? If the lake on my farm is a sanctuary for migratory birds, shouldn't bird lovers pay me not to drain it for conversion into farm land? Never mind that the market for ecosystem services would be thin, if a system involving PES were put in place, owners of ecological capital and beneficiaries of ecological services would be forced to negotiate. The former group would then have an incentive to conserve their assets (Daily and Ellison, 2002;

11 For a more comprehensive study of ecosystem services produced by avians, see Sekercioglu et al. (2004). 
Pagiola et al., 2002; Goldstein et al., 2006). In a review of current practices, Jack et al. (2008) note that hundreds of new PES schemes have been established round the globe. China, Costa Rica, and Mexico, for example, have initiated large-scale programmes in which landowners receive payment for increasing biodiversity conservation, expanding carbon sequestration, and improving hydrological services.

Although we have no firm empirical understanding of processes in which a single agent is engaged in multiple bilateral negotiations over the supply of what amounts to a "public good", we do have some theoretical understanding. Consider a situation in which the farmers in our example are willing to negotiate with the timber firm. It can be shown that if the parties discount future profits at a very low rate, all but one farmer would free ride and enjoy the benefit (i.e., they would make no payment to the firm). So farmers have no incentives to form a coalition among themselves. Moreover, the (equilibrium) outcome isn't unique, meaning that the farmer who negotiates with the firm isn't necessarily the one who would be worst affected by deforestation. ${ }^{12}$

Although PES may be good for conservation, one can imagine situations where the system would be bad for poverty reduction and distributive justice. Many of the rural poor in poor countries enjoy nature's services from assets they don't own. Even though they may be willing to participate in a system of property rights in which they are required to pay for ecological services (Pagiola et al. 2008, report in their careful study of a silvo-pastoral project in Nicaragua that they do), it could be that in the world we have come to know, the weaker among the farmers are made to pay a disproportionate amount. Some may even become worse off than they were earlier (Dasgupta and Heal, 1979: Ch. 3). One could argue that in those situations the state should pay the resource owner instead, using funds obtained from general taxation. As Reid et al. (2003), Bulte et al. (2008) and Zilberman et al. (2008) observe, who should pay depends on the context.

A PES system in which the state plays an active role is attractive for wildlife conservation and habitat preservation. In poor countries property rights to grasslands, tropical forests, coastal wetlands, mangroves, and coral reefs are often ambiguous. The state may lay claim to the assets ("public" property being the customary euphemism), but if the terrain is difficult to monitor, inhabitants will continue to reside there and live off its products. Inhabitants are therefore key stakeholders. Without their engagement the ecosystems couldn't be protected. Meanwhile flocks of tourists visit the sites on a regular basis. An obvious thing for the state to do is to tax tourists and use the revenue to pay local inhabitants for protecting their site from poaching and freeriding. Local inhabitants would then have an incentive to develop rules and regulations to protect the site.

But even if inhabitants as a collective are given an incentive to self-regulate, individual members may not have the incentives to conform to communitarian rules and regulations. The economics of "common property resources" studies ways in which individual incentives can be aligned to communitarian goals. We discuss that next.

\section{Reciprocal Externalities: Common Property Resources (CPRs)}

Who owns the local natural-resource base in rural areas? Anthropologists, economists, and political scientists working at the fringes of official development economics have discovered that, barring agricultural land, ecological capital is often neither private nor state property. Nor are

12 See Dasgupta and Sabourian (2008). 
they "open access" resources. They are communal property, which is why they are called common property resources, or CPRs. If CPRs are badly managed, households in the community freeride, and the commons suffer from excessive use. The point of communal management is to restrict use (e.g. by establishing charges or quantity restrictions) and fend off a possible "tragedy of the commons".

\subsection{Why CPRs?}

As a proportion of total assets, CPRs range widely across ecological zones. In India they are most prominent in arid regions, mountain regions, and un-irrigated areas; they are least prominent in humid regions and river valleys (Agarwal and Narain, 1989; Chopra et al., 1990). There is a rationale behind this, based on the need to pool risks. Woodlands, for example, are spatially inhomogeneous ecosystems. In some years one group of plants bears fruit in one part of a woodland, in other years some other group in some other part is fecund. Relative to mean output, fluctuations could be presumed to be larger in arid regions, mountain regions, and un-irrigated areas. If a wood-land were to be divided into private parcels, each household would face greater risks than it would under communal ownership and self regulation. The reduction in individual household risks may be small, but as average incomes are very low in Indian villages, household benefits from communal ownership could be expected to be large.

Where users are symmetrically placed, distributions would be expected to be symmetric, a subtle matter to devise if the resource is heterogeneous. Rotation of access to the best site is an example of how this can be achieved. It is often practised in coastal fisheries, fuel reserves in forest land, and fodder sites in the grasslands (Baland and Platteau, 1996). Rotation enables users to get a fair shake.

Of course, it would be possible in principle for the community to parcel out the resource as private property and let households establish a mutual insurance scheme. But that move would jeopardize cooperation in other activities; for at least two reasons. First, cooperation appears to be habit forming (Seabright, 1993); so, dispensing with cooperation in any one activity could lead to a weakening of cooperation in other activities. Secondly, cooperation is more robust when sanctions for opportunism in any one venture include exclusions not only from that venture, but also from other collective ventures. Abandoning cooperation in one field of activity thus reduces the robustness of cooperation in other fields of activity. This fact is an implication of the theory of repeated games. It explains why relationships are so frequently tied to one another in rural communities (Dasgupta, 2007a).

Local ecosystems are frequently CPRs also because their constituents are mobile. Birds and insects fly, fish swim, inorganic materials defuse in space, and even earthworms are known to travel. Their mobility integrates an ecosystem's various components. Ecosystem dynamics are non-linear, involving positive feedback in a wide range of states, meaning that the system as a whole is greater than the sum of its spatial parts. Ecosystems therefore have an element of indivisibility to them. If you slice off a significant portion for some other purpose, the productivity (e.g., biomass production) per unit area of what remains is reduced. But even if it were decreed that no portion could be converted for another use, parcelling ecosystems into private bits would be inefficient because of the externalities that are created by the mobile components. Admittedly, private monopoly would avoid the externalities, but it would grant far too much power to one person in the community. 
Agricultural land, especially in densely populated areas, is a different matter. Both labour and capital are critical inputs in production. Investment can increase land's productivity enormously. Agricultural land as CPRs would be subject to serious management problems, including those due to the temptations to free ride on investment costs. The lack of incentives to invest and innovate would lead to stagnation, even decay. The fate of collective farms in what was previously the Soviet Union testifies to that. Those regions of sub-Saharan Africa where land is, or was until recently, held by the kinship were exceptions, but only because land was plentiful in the past and because poor soil quality meant that land had to be kept fallow for extended periods. Of course, it may be that agricultural productivity remained low there because land was held by the kinship, not by individuals. As elsewhere in the social sciences, causation typically works in both directions.

\subsection{The Importance of CPRs}

Are CPRs important to rural people? Jodha (1986) reported evidence from a number of dry rural districts in India that the proportion of income among poor families that is based directly on CPRs is $15-25 \%$. Cavendish (2000) has arrived at even larger estimates than Jodha from a study of villages in Zimbabwe: the proportion of income based directly on CPRs is 35\%, the figure for the poorest quintile being 40\%. At a country level, some 5 billion US dollars of products are drawn from CPRs annually by the Indian rural poor (Beck and Nesmith, 2001). Wood-fuel is prominent among CPR products. It is estimated that some 2.4 billion of the world's poor depend on wood or other biomass fuels for cooking and heating (World Resources Institute, 2005). That is why the finding by Cook et al. (2008) that community forestry in poor countries continues to ignore the importance of wood-fuel among rural households is ironic.

Marine fisheries are a major source of food and income among the coastal poor. Some 250 million of the world's poor depend on coastal CPRs. Such evidence doesn't of course prove that CPRs are well managed, but it does show that rural households have strong incentives to devise arrangements whereby they are managed.

CPRs not only supply households with a regular flow of ecosystem services and tangible goods (water, fuel-wood, fibres, building material, fruit, honey, and fish), they also offer protection against agricultural risks. In a study of households on the margin of the Tapajos National Forest in the Brazilian Amazon, Pattanayak and Sills (2001) found that households make more trips into the forest for non-timber products when times are hard. CPRs are sometimes the only assets to which the otherwise disenfranchised have access. Hecht et al. (1988) have described the importance of babassu products among the landless in Maranho, Brazil. Extraction from those plants offers support to the poorest of the poor, most especially women. The authors reported that babassu products are an important source of cash income in the period between agriculturalcrop harvests. Economic theory says that where there is a market for labour even the casual wage rate of unskilled labourers would be higher in villages with more abundant CPRs (Dasgupta, 1993). There is evidence of this (Barbier, 2005). That said, I am not implying that asset-less people featured prominently in community decisions to create the institutions that govern CPRs, I am merely drawing attention to a good feature of CPRs.

\subsection{The Good News about CPRs}

Most often CPRs aren't open to outsiders, but only to those having historical rights through kinship ties and community membership. Communal management of local resources makes 
connection with social capital, viewed as a complex of interpersonal networks, and hints at the basis upon which cooperation has traditionally been built. As CPRs have been seats of nonmarket relationships, transactions involving them are often not mediated by market prices. So their fate is frequently unreported in national economic accounts. However, a large empirical literature has confirmed that resource users in many cases cooperate, on occasion through democratic means. The empirical literature on CPRs is now huge (Netting, 1985; Jodha, 1986, 2001; National Research Council, 1986, 2002; Wade, 1988; Chopra et al., 1989; Feeny et al., 1990; Ostrom, 1990, 1992; Bromley et al., 1992; Baland and Platteau, 1996, 1999; Noronha, 1997; Kadekodi, 2004; Baland et al., 2007; and Ghate et al., 2008, among many others). The economic theory of CPRs was however constructed earlier, in Dasgupta and Heal (1979: Ch. 3).

Are CPRs managed communally? Not invariably, but in many cases they are, or have been in the past. Wade (1988) reported his findings from a study of community-based allocation rules over water and the use of grazing land in 41 South Indian villages. He noted that downstream villages had an elaborate set of rules for regulating the use of water from irrigation canals. Fines were imposed on those who violated the rules. Most villages had similar arrangements for the use of grazing land.

In a study on forest conservation in the central Himalayas, Somanathan et al. (2005) have found that the density of broad-leaf trees was significantly higher in places where the forest was managed by village councils than in areas where neither councils nor the state was involved in forest management.

Of course, cooperation doesn't appear in vacuum. In the contemporary world there is a potential role of government and non-government organizations (NGOs) in helping to build or rebuild local institutions through which communities could get to realize the advantages of collective action. Such help would involve, among other things, devising clearly-defined rules concerning the allocation of burdens and benefits, rules whose compliance can be observed (hopefully, verified also) by others involved. In a study in North-West India, Chopra and Gulati (1998) found that distress migration out of villages where NGOs had been at work to create institutions for managing water and pasture land on a communal basis was lower than in villages where there had been little attempt to create such institutions. Significantly, Chopra and Gulati found that the probability of participation in communal pasture land was higher among villagers who were participating in communal water management schemes than among villagers who were not. That suggests once again that cooperation begets cooperation.

How is cooperation maintained? Universally, studies have found that collective sanctions are imposed on those who misbehave (see e.g. Baland and Platteau, 1996). Today the underlying mechanism is common knowledge among economists. The theory of repeated games has shown that so long as households don't discount future costs and benefits at too high a rate and so long as behaviour is mutually observable, social norms involving the use of sanctions on non-cooperative behaviour enable cooperation to be maintained. Sanctions range from the punitive and unforgiving (permanent exclusion following a single misdemeanour; widely know in the economic literature as the "grim" norm) to the forgiving (as in graduated sanctions; see below). The grim norm has been found in reciprocal relationships (Czako and Sik, 1988), but appears to be in force only in those environments where the parties have access to formal markets as an alternative. Something like "grim" is needed for preventing people from engaging in non-cooperative behaviour in an environment where tempting, short-term opportunities appear elsewhere from time to time. 
Outside opportunities are often rare in rural communities that are to all intents and purposes enclaves. Communitarian arrangements there are of high value to all and matters are different. Graduated sanctions are in wide use. The first misdemeanour is met by a small punishment, subsequent ones by a stiffer punishment, persistent ones by a punishment which is stiffer still, and so forth (see e.g. Ostrom, 1992). Where information is imperfect, a small penalty for the first misdemeanour could be a warning that others are watching, or it could be that others signal their acknowledgement that the misdemeanour could have been an error on the part of the offender and that he should try harder next time. And so on.

\subsection{The Bad News about CPRs}

So far, the good report on CPRs. There are, however, two pieces of bad news. The first involves resource allocation in communitarian institutions. Entitlements from CPRs are frequently based on private holdings: richer households enjoy a greater proportion of the benefits. Beteille (1983), for example, drew on examples from India to show that access to CPRs is often restricted to the elite (e.g., caste Hindus). Cavendish (2000) has reported that in absolute terms richer households in his sample of villages took more from CPRs than poor households. In an early review, McKean (1992) noted that benefits from CPRs are frequently captured by the elite. Agarwal and Narain (1996) exposed the same phenomenon in their study of water management practices in the Gangetic plain, as did Bardhan and Dayton-Johnson (2007) in a study of irrigation systems in Mexico and South India.

However, the relative exploitation of CPRs by the poor and the not-so-poor isn't uniform across the world. In two large scale studies of household data in India and Nepal, respectively, Bandopadhyay and Shyamsundar (2004) and Bandopadhyay et al. (2006) found that woodfuel consumption decreases with wealth in India, but increases with wealth in Nepal. Their finding suggests that the availability of cheap substitutes matters. In India, where rural markets are more developed than in Nepal, relatively wealthy households are able to save on labour costs by buying fuel in the market place.

That women are sometimes excluded from CPRs has been recorded in communal forestry (B. Agarwal, 2001). It is even possible that the elite exploit others, in the strong sense that the latter are worse off when the CPR is regulated than they would have been if the CPR was unregulated (Dasgupta, 2000; see also Dasgupta, 2008a). But because cooperation in one activity is usually tied to cooperation in other activities, it would be hard to establish empirically that one group of CPR users is exploiting another group of users.

The second piece of bad news is that CPRs have deteriorated in recent years in many parts of the poor world (Perrings, 2000; Jodha, 2001; Hassan et al., 2005). Why should that have happened in those places where they had been managed in a sustainable manner previously? There are several reasons:

One stems from deteriorating external circumstances, under which both the private and communal profitability of investment in the resource base decline. Political instability is a general cause. It is, of course, a visible cause of resource degradation, as civil disturbance all too frequently expresses itself by a destruction of physical capital. But increased uncertainty in communal property rights is a frequent, often hidden cause. People could worry that the state or warlords will assume authority over the CPRs. If the security of a CPR is uncertain, the returns expected from collective 
action are low. The influence would run the other way too, with growing resource scarcity contributing to political instability, as rival-groups battle over resources. The feedback could be "positive", exacerbating the problem for a time, thus reducing expected returns yet further.

The second reason CPRs have deteriorated in many places is rapid population growth. The latter triggers environmental degradation if institutional practices are unable to adapt to the increased pressure on resources. In Cote d'Ivoire, for example, growth in rural population has been accompanied by increased deforestation and reduced fallows. Biomass production has declined, as has agricultural productivity (Lopez, 1998). Leisinger et al. (2002) offer a wide-ranging discussion of the deleterious effects of recent population growth on food security in poor regions.

However, rapid population growth in the world's poorest regions in recent decades itself requires explanation. Demographers have argued that a fall in the child mortality rate (which is otherwise a very good thing) is a major factor (Bhargava, 2008, identifies reasons why even fertility rates respond to declines in child mortality with a lag). Here I suggest factors that haven't been much studied by demographers. Increased economic insecurity, owing to deteriorating institutions, is one: children yield a higher private return in such circumstances than other forms of capital assets (Bledsoe, 1994; Guyer, 1994; Heyser, 1996). Reproductive activity also involves a number of externalities that encourage people in the world's poorest regions to be pro-natalists (Dasgupta, 2003). To take an example, consider that when institutions governing the CPRs deteriorate, households free-ride on the resource base. As some of the cost of maintaining a household is passed on to others, the net private benefits of accumulating more "hands" to mine the CPRs can increase. Dasgupta and Mäler (1991) and Nerlove (1991) argued that receding firewood and water sources may increase the household demand for labour, leading to a rise in household size. In an analysis of data from South Africa, Aggarwal et al. (2001) have found a positive link between fertility increase and degradation of CPRs. Filmer and Pritchett (2002) have reported a weak positive link between the two in the Sindh region in Pakistan.

On the other hand, Loughran and Pritchett (1998) found evidence in Nepal that more acute resource scarcity was associated with lower fertility, which suggests that growing scarcity there raised the net cost of having children. Apparently, increasing firewood and water scarcity in the villages in the sample didn't have a strong enough effect on the relative productivity of child labour to induce higher fertility. It seems then that the relationship between resource scarcity and fertility can be of either sign. ${ }^{13}$ Admittedly, none of the empirical studies just mentioned quite captures what the theory I am alluding to here tells us to study, namely, the link between desired household labour and the state of the local natural-resource base; but they come close enough.

The third reason CPRs have deteriorated in some places is that communal rights were overturned by central fiat. In order to establish its political authority, a number of states in the Sahel, for example, imposed rules that destroyed communal management practices in the forests. Villages ceased to have the authority to enforce sanctions on those who broke communitarian rules. But state officials didn't have the expertise to manage the commons, often they were corrupt. Knowledge of the local ecology is held by those who work on the commons. Local participatory democracy offers a mechanism by which that knowledge can inform public policy. Isham et al. (1995) found strong evidence from 121 rural water projects (in 49 countries in Africa, Asia and Latin America) that participation by beneficiaries is positively correlated with project performance.

13 Dasgupta (2003: Appendix) contains a formal model that identifies conditions for each possibility. 
Relatedly, Thomson et al. (1986), Somanathan (1991), and Baland and Platteau (1996), among others, have identified the many ways by which the exercise of state authority damages local institutions and turn CPRs into open-access resources. In their study of forest management in the central Himalayas, Somanathan et al. (2005) found that crown cover was no less in places that were governed by village councils than it was in areas managed by the state, but expenditure on governance was an order of magnitude higher in the latter places.

Democratic movements among stakeholders and pressure from international organisations have encouraged a return to communitarian management systems. Shyamsundar (2008) is a remarkable synthesis of the findings in nearly 200 articles on the efficacy of devolution of management responsibilities - from the state to local communities - over the local natural-resource base. Her article focuses on wildlife, forestry, and irrigation. The balance of evidence appears to be that devolution leads to better resource management, other things being equal. Shyamsundar of course offers a discussion of what those other things are.

The fourth reason CPRs have deteriorated in many places is that cooperation is fragile, dependent as it is on many factors that have to work simultaneously in its favour. For example, in the face of growing opportunities for private investment in substitute resources, households are more likely to break agreements that involve reciprocity (Dasgupta, 1993, 2007; Campbell et al., 2001). But when traditional systems of management collapse and aren't replaced by adequate institutions, CPRs suffer from neglect. Here are three examples illustrating the phenomenon:

1. Mukhopadhyay (2008) is a historical study of the transformation of agrarian land in Goa, India, that was earlier owned and regulated by a communitarian institution called the communidades. When Goa became a part of India, the government introduced land reforms that gave tenants the right to purchase the land they had worked. Mukhopadhyay doesn't question the underlying motivation behind land reforms, but notes one unfortunate consequence, which is the breakdown of cooperation among households in maintaining the embankments that had earlier prevented the land from flooding by tidal waters. Over the years deterioration of the embankments has led to an increase in soil salinity.

2. In her study of collectively managed irrigation systems in Nepal, Ostrom (1996) accounted for differences in rights and responsibilities among users (who gets how much water and when, who is responsible for which maintenance task of the canal system, and so forth) in terms of the fact that some farmers are head-enders, while others are tail-enders. Headenders have a built-in advantage, in that they can prevent tail-enders from receiving water. On the other hand, head-enders need the tail-enders' labour for repair and maintenance of traditional canal systems, which are composed of head-works made of stone, trees, and mud. Ostrom reported that a number of communities in her sample had been given wellmeaning aid by donors which installed permanent head-works. What could be better, you may ask. But Ostrom observed that those canal systems that had been improved were frequently in worse repair at the tail end and were delivering less water to tail-enders than previously. Ostrom also reported that water allocation was more equitable in traditional farm management systems than in modern systems managed by external agencies, such as government and foreign donors. She estimated from her sample that agricultural productivity is higher in traditional systems.

Ostrom's explanation for this is that unless it is accompanied by counter-measures, the construction of permanent head-works alters the relative bargaining positions of the head- 
and tail-enders. Head-enders do not now need the labour of tail-enders to maintain the canal system. So the new sharing scheme involves even less water for tail-enders. Headenders gain from having the permanent structures installed, but tail-enders lose. This is an example of how well-meaning aid can go wrong if the nature of the institution receiving the aid is not understood by the donor.

3. Village tanks are one of the oldest sources of irrigation in South Asia. In a study of a group of villages in southern India, Balasubramanian (2008) reports that village tanks have deteriorated over the years owing to a decline in collective investment in their maintenance. That decline has taken place as richer households have invested increasingly in private wells. As poor households depend not only on tank water but also on the fuel-wood and fodder that grow round the tanks, construction of private wells has accentuated economic stress among the poor.

And fifthly, an erosion of CPRs can come in the wake of shifting populations accompanying the development process itself (Dasgupta, 2000). As economic opportunities outside the village improve, those with lesser ties (e.g. young men) are more likely to take advantage of them and make a break with customary obligations. Those with greater attachments (e.g. women) would perceive this and thereby discount at a higher rate the benefits that could be expected from complying with agreements. Either way, norms of reciprocity could be expected to break down, making certain groups of people (women, children, the aged) worse off.

History tells us that CPRs can be expected to decline in importance as economies develop (North and Thomas, 1973). Ensminger's (1992) study of the privatization of common grazing lands among the Orma in north-eastern Kenya established that the transformation took place there with the consent of the elders of the tribe. She attributed the move to cheaper transportation and widening markets, making private ownership of land more profitable. However, as the elders were from the stronger families, privatization accentuated inequality within the tribe. The point isn't to lament the decline of the commons; rather, it is to identify those who are likely to get hurt by changes in economic regimes and the accompanying transformations in the use to which the resources are put. That there are winners in the process of economic development is a truism. Much the harder task is to identify the likely losers and have policies in place that act as safety nets for them. In what follows we study policy evaluation and institutional reform when ecological capital is included in the exercise.

\subsection{Valuation, Evaluation, and Sustainable Development}

In evaluating an economy, there are five questions we can ask: (A) How is the economy doing? (B) How has it performed in recent years? (C) How is it likely to perform under "business as usual"? (D) How is it likely to perform under alternative policies? (E) What policies should be pursued there?

National income accounts offer information relevant for answering question (A), although I argue below that they do so in an unsatisfactory way. Policy evaluation, including project evaluation, is a way to answer questions (D) and (E). The idea is to evaluate an economy at a point in time before and after a hypothetical perturbation has been made to it. In contrast, the literature on "sustainable development" answers questions (B) and (C) by evaluating economic change when 
the perturbation is the passage of time itself.

Question (A) stands apart from questions (B) to (E), at least if conventional practice among national income statisticians is any guide. For it is common practice to summarize the state of an economy by its GDP, or equivalently its (gross) domestic income.

\section{Inadequacies in GDP}

A good history of the concepts of GDP and national income was provided by Richard Stone in his Nobel Lecture, which is available on the home page of the Nobel Foundation. But even a cursory study tells us that GDP rose to prominence during the 1930s, when industrial nations were suffering from economic depression. At that time there was a need to find an index of aggregate economic activity. GDP filled that need. During the post-War years, though, GDP came to be regarded as a welfare index. That interpretation is now so ingrained in us that it has become common practice to use estimates of GDP growth for answering questions (B) to (E). Indeed, if someone talks of economic growth, the listener doesn't need to ask, "Growth in what?" he will know that the speaker means growth in GDP.

The use of GDP as a welfare index has been much criticized on grounds that it is insensitive to distributional concerns. But the criticism would be met if distributional weights were applied to different income groups (Dasgupta et al., 1972). The real weakness of GDP as a welfare index lies elsewhere. Economic growth is no doubt a good thing - it usually purchases a better quality of life - but as we shall see presently, studying movements in GDP is of no use in ascertaining whether economic growth is compatible with "sustainable development".

A famous report by the World Commission on Environment and Development (1987) - known widely as the Brundtland Report - defined sustainable development as "... development that meets the needs of the present without compromising the ability of future generations to meet their own needs." In their version "sustainable development" requires that relative to their populations, each generation should bequeath to its successor at least as large a productive base as it had itself inherited. Notice that the requirement is derived from a relatively weak notion of intergenerational equity. Sustainable development demands that future generations have no less of the means to meet their needs than we do ourselves. It demands nothing more; it doesn't, for example, demand that development be optimal or just. But how is a generation to judge whether it is leaving behind an adequate productive base for its successor? ${ }^{14}$

It is clear that tracking GDP won't do. GDP is a linear index of the final goods and services. Even though it has been argued that the weights attached to goods and services ought to be shadow prices (Mirrlees, 1969; Sen, 1976), national income statisticians use market prices, shorn of taxes and subsidies. As large numbers of ecological services in poor countries are transacted in non-market institutions, official GDP mis-specifies the level of economic activity. But there is a more fundamental problem with GDP: the index mismanages inter-temporal considerations badly. (We confirm below that the United Nations' Human Development Index suffers from that same weakness.) The point is that GDP ignores the depreciation of capital assets. Among natural resources, that depreciation can range from a full $100 \%$ of the services drawn from oil and

14 Pezzey (1992) and Pezzey and Toman (2002) discuss various ways of defining sustainable development. Here I am following the literature that has related the concept to welfare economics. 
natural gas, to the degradation of ecosystems through mismanagement. As natural capital is especially vulnerable to overuse, serious criticisms of GDP were first made in the context of environmental and natural resource problems. ${ }^{15}$

We may put the matter another way: GDP measures the aggregate income of the current generation, whereas in seeking to determine the sustainability of economic development, we should be interested in the well-being of current and future generations. So, by social well-being we will mean an ethically defendable numerical index of the well-beings of the present and future generations. As the future is uncertain, the numerical index is taken to include an ethically defendable attitude toward that uncertainty. In Section 12 (where I review the welfare theory underlying the economics of climate change) and the Appendix (where formal accounts of policy evaluation and sustainable development are illustrated), social well-being is understood to be a generalized form of Utilitarianism. In what follows I drop further reference to uncertainty (but see Section 12.4 on the economics of climate change ) and assume simply that the index of social well-being reflects it.

\section{Valuing Goods and Services}

Evaluating an economy requires that we value goods and services from a societal point of view. The social values of goods and services are called shadow prices, a familiar term in development economics. In order to keep the analysis neutral across commodities, let social well-being be the numeraire.

\subsection{Defining Shadow Prices}

In public economics shadow prices are defined as the difference between market prices and optimum taxes or subsidies (Atkinson and Stiglitz, 1980). This is too narrow a base on which to build policy analysis in rural economies, where transactions are frequently based on communitarian relationships. Moreover, the term "optimal" can rarely be applied to policies chosen there. So we revert to the mathematical definition.

Definition 1. Suppose at date t an economy is awarded an additional unit of some asset free of charge. The asset's shadow price is the resulting change in social well-being.

The Appendix provides the mathematical counterpart of Definition 1 (equation (A.6)). But the definition already tells us that three pieces of information are required for estimating shadow prices:

(i) Adescriptive model of the economy.

(ii) The size and distribution of the economy's capital assets.

(iii) A conception of social well-being.

Requirements (i) and (ii) are the basis for estimating the changes that take place in the allocation

15 See Nordhaus and Tobin (1972), Mäler (1974), Mäler and Wyzga (1976), Dasgupta and Heal (1979), Hartwick (1990, 2000), Lutz (1993), and Aronsson et al. (1997), among others. Mäler (1991) and Weale (1997) provide outlines of a complete system of national accounts inclusive of environmental natural resources. Lange et al. (2003) and Perrings and Vincent (2003) contain applied studies on both valuation and resource accounts. 
of resources if an additional unit of the asset is made available free of charge. Requirement (iii) is the basis for placing a value on that change. Dasgupta (1982) used Definition 1 to argue that even in imperfect economies the dynamics of ecosystems have to be taken into account explicitly if we are to estimate the shadow prices of natural resources and environmental pollutants.

At any date an asset's shadow price is a function of the stocks of all assets. Moreover, the price today depends not only on the economy today, but on the entire future of the economy. Future scarcities of ecological capital are reflected in current shadow prices of all goods and services. So shadow prices are functions of the degree to which various assets are substitutable for one another, not only at the date in question, but at all subsequent dates as well. Of course, if the conception of social well-being involves the use of high discount rates on the well-being of future generations, the influence on today's shadow prices of future scarcities would be attenuated. Intergenerational ethics plays an important role in the structure of shadow prices, a fact that was displayed in the contrasting recommendations of Cline (1992) and Stern (2006) on the one hand and Nordhaus $(1994,2008)$ on the other, over how much the world community should spend now to meet the problems of global warming (Section 12.3). In imperfect economies (e.g., those experiencing the tragedy of the commons) an asset's shadow price can be negative even when its market price is positive.

\subsection{Estimating Shadow Prices}

How should shadow prices be estimated? Consider the human capital asset we call "health". Suppose we wish to value a marginal increase in life expectancy. Economists have followed two ways to do this. One is to estimate the (social) cost of bringing about that increase. The other is to estimate the value of the increase in life expectancy itself. The two would lead to the same estimate at a full optimum, but not in imperfect economies, where the latter is the right way to go about the matter (Definition 1 and equation (A.6)). But as the latter requires us to estimate the value of a statistical life (Viscusi and Aldy, 2003), the method has proved to be controversial when deployed for making cross country comparisons. Arrow et al. (2004) used figures for public health expenditure for the shadow price of health improvements in poor countries, while Arrow et al. (2008) have combined age-specific mortality tables with values of statistical life years so as to estimate the shadow price of increases in life expectancy. The latter estimates have been found to be substantially higher than the former, implying that the economies in their sample of countries are highly imperfect.

Using Definition 1 directly is problematic because of the enormous quantity of information demanded by requirements (i)-(iii). So environmental and resource economists have devised two indirect methods (Freeman, 1992; Smith, 1997 are fine expositions of the methods). In one, investigators ask people to place a value on ecological resources. In the other, they study behaviour and the consequences of that behaviour to infer the value individuals place on those assets. In the latter method, market prices of those goods and services for which there are markets are often taken to be their shadow prices. As an example of the latter, consider an asset that has multiple characteristics (e.g., land). The hedonic method uses the market price of a piece of land to uncover the shadow price of one of its characteristic (e.g., the price of its aesthetic qualities). The hedonic method has been much used to value real estate. In their work on inland wetlands in eastern North Carolina (USA), Bin and Polasky (2004) found that, other things being equal, proximity to wetlands lowered property values, presumably because of a greater infestation of insects and possibly bad odour. 
The valuation methods that have become most popular were devised for environmental amenities, such as places of scenic beauty or cultural significance. The cost of travel to a site takes revealed preference to be the basis for valuing the site. Englin and Mendelsohn (1991), for example, is a well-known application of the method for estimating the recreation value of forests. In contrast, in those cases where there is no observed behaviour, the contingent valuation method (CVM) has proved to be extremely popular (see Carson, 2004, for an extensive bibliography and Smith, 2004, for an excellent history of the method). The idea is to ask people how much they would be willing to pay for the preservation of an environmental amenity (e.g., flood control) or a resource of intrinsic worth (e.g., an animal or bird species).

Each of the above methods is of limited use for valuing the local natural resource base in the poor world. Moreover, one can question whether requirements (i)-(iii) can be met adequately by studying people's behaviour or analysing their responses even to well-designed questions. One reason for being circumspect about those methods (there are many other reasons) is that people often aren't aware of environmental risks. Jalan and Somanathan (2008) conducted an experiment among residents of a suburb of New Delhi. The aim was to determine the value of information on the health risks that arise from drinking water that contained bacteria of faecal origin. Without purification the piped water in $60 \%$ of the households were found to be contaminated. Among households in the sample that had not been purifying their piped water, some were informed by the investigators that their water was possibly contaminated, while the rest were not informed. The authors report that the former group of households was $11 \%$ more likely to invest in purification within the following 8 weeks than the latter group. An additional year of schooling of the most educated male in the household was associated with a 3\% increase in the probability that its piped water was being treated. The finding is noteworthy because the wealth and education levels of households in the sample were above the national average. If ignorance of environmental risks is pervasive, estimates of the demand for environmental quality that assume full information must be misleading. ${ }^{16}$

So we return to requirements (i)-(iii). In their work on the economics of climate change, Cline (1992) and Stern (2006) met (i) and (iii) directly (Section 12.3). Several recent valuation studies have met requirement (i) by estimating the production function for nature's service (e.g., pollination as a function of the distance to a forest; primary productivity as a function of biodiversity; net reproduction rate of a species), but have otherwise assumed that market data are more or less sufficient to meet the other requirements. ${ }^{17}$ Pattanayak and Kramer (2001) and Pattanayak and Butri (2005), for example, constructed a hydrological model to measure the contribution of upland forests to farm productivity downstream. Hassan (2002) used quantitative models of woody land resources in South Africa to estimate the value to rural inhabitants of (among other resources) the Fynbois Biome, which dominates sandy soils there. Barbier (1994) and Gren at al. (1994) used formal ecological models to compile a catalogue of the various services that are provided by wetlands. In their study of wetlands in northern Nigeria, Acharya (2000) and Acharya and Barbier (2000) applied models of ground water recharge to show that the contribution wetlands make to recharging the basins is some $6 \%$ of farm incomes. That's a large figure.

16 Determining the "willingness to pay" for changes in risk involves additional problems. See Smith and Desvouges (1987).

17 See Dasgupta (1982), Dobson et al. (1997), Barbier (2000), Turner et al. (2000), and Tilman et al. (2005) for illustrations of ecosystem production functions and the corresponding dynamics of the socio-ecological systems. 
The welfare economics of climate change requires that carbon in the atmosphere is priced. The early literature on the subject didn't have a spatial component to that price. A figure of $20 \mathrm{US}$ dollars per ton for carbon's global shadow price was suggested by Fankhauser (1995) and Pearce et al. (1996). That figure has been used in the World Bank's work on sustainable development (Section 10.2). But there are likely to be enormous regional variations in the impact of global climate change on economic activity (Rosenzweig and Hillel, 1998; Mendelsohn et al., 2006; Dinar et al., 2008). Agriculture in semi-arid tropical countries is expected to suffer from warming, while in temperate regions it will probably benefit. If we apply distributional weights to the losses and gains, the disparity is bigger than the nominal figures that have been suggested, because the former group of countries are almost all poor while the latter are middle-income to rich. Using a range of climate models, Mendelsohn et al. (2006) have published estimates of losses and gains in year 2100. The authors aggregated five sectors: agriculture, water, energy, timber, and coasts. Depending on the scenario, they found that the poorest countries (almost all in Africa) are likely to suffer damages from $12 \%$ to $23 \%$ of their GDP, while the range of impacts on the richest countries (North America and northern Europe) is from damages of $0.1 \%$ to a gain of $0.9 \%$ of their GDP. Dinar et al. (2008) fear that with warming, the agricultural income in the semi-arid tropics could be more than halved in 2100 from its projected value in the case where there is no warming. But these estimates are based on market prices. If distributional weights are applied to obtain a global shadow price of carbon, it would be a lot higher than if we were merely to add the regional gains and losses. It should also be noted that the effects of climate change on health and the environment (e.g. loss of species) were not included in those estimates.

Determining the shadow prices of ecological capital assets should now be central to the research agenda in development economics. Hassan et al. (2005) and Carpenter et al. (2005) contain the kind of information that would prove useful in such exercises. We would have been far ahead in the development of policies that help to alleviate poverty in poor countries had development economists and policy makers taken natural capital seriously in the past.

What is the point of basing shadow prices solely on one particular use-value when we know that natural capital often possesses other values too? The answer is that the method provides us with biased estimates of shadow prices. That can be useful information. For example, in a beautiful paper on the optimal rate of harvest of blue whales, Spence (1974) took the shadow price of whales to be the market value of their flesh, a seemingly absurd and repugnant move. But on estimating the population growth functions of blue whales and the harvest-cost functions, he found that under a wide range of plausible parameter values it would be most profitable commercially for the international whaling industry to agree to a moratorium until the desired long-run population size was reached, and for the industry to subsequently harvest the whales at a rate equal to the population's optimal sustainable yield. ${ }^{18}$ In Spence's analysis, preservation was recommended solely on commercial ground. But if preservation is justified when the shadow price of blue whales is estimated from their market price, the recommendation would, obviously, be reinforced if their intrinsic worth were to be added. This was the point of Spence's exercise.

18 During the moratorium the whale population grows at the fastest possible rate. In Spence's numerical computations, the commercially most-profitable duration of the moratorium was found to be some 10-15 years. 


\section{Social Well-Being and Comprehensive Wealth}

Social well-being is very difficult to estimate directly because it is a non-linear function of the flow of goods and services. We seek a linear index that moves in unison with social well-being. Shadow prices are essential for the task.

\subsection{A Unifying Model}

Imagine that we have estimated shadow prices on the basis of the information covering requirements (i)-(iii). Let us now use those prices as weights to construct an aggregate index of the economy's comprehensive stock of capital assets. The assets on the list include not only reproducible capital (roads, buildings, machines, instruments) and human capital (health, human talents, education), but also population numbers and natural capital. Moreover, the list contains "knowledge", including scientific and technological knowledge, and institutional capabilities.

It is typically assumed in economic models, though, that changes in some of the economic variables are exogenous. Growth or decline in population, and movements in total factor productivity (TFP) and the price of imports are typical examples. Below I show that an obvious way to accommodate exogenous changes in economic variables is to regard time also as a capital asset.

Call the aggregate index of the economy's comprehensive stock of capital assets we have thus constructed, its comprehensive wealth. Formally

Definition 2. An economy's comprehensive wealth is the (shadow) value of all its capital assets.

We will find it useful to separate time from all other assets. So let all capital assets excepting for time be indexed by $i$. Let $\mathrm{K}_{\mathrm{i}}(t)$ be the stock of asset $i$ at time $t(\geq 0)$ and $\underline{K}(t)$ the corresponding vector of assets. We assume that none of the $\underline{K}_{i}$ is a global public good (but see Section 10.2). Let $V(t)$ be social well-being at $t$. We know that $\mathrm{V}(t)=\mathrm{V}(\underline{K}(t), t)$. In the Appendix we study the standard representation of $V(t)$. Let $p_{i}(t)$ be asset i's (spot) shadow price (i.e. $p_{i}(t)=\partial V(t) /$ $\partial K_{i}(t)$; see Appendix) and $r(t)$ the (spot) shadow price of time (i.e., $\left.r(t)=\partial V(t) / \partial t\right)$; see appendix). Writing W(t) for the economy's comprehensive wealth at $t$, we have

$$
W(t)=r(t) t+{ }_{i} \Sigma\left[p_{i}(t) K_{i}(t)\right]
$$

Why should we be interested in comprehensive wealth? The reason lies in

Proposition 1: A small perturbation to an economy increases (resp., decreases) social wellbeing if, and only if, holding shadow prices constant, it increases (resp., decreases) comprehensive wealth. ${ }^{19}$

Proof: Let $\Delta$ denote a small perturbation. Assuming $V$ is differentiable, we have

19 This finding has been proved with increasing generality by Hamilton and Clemens (1999), Dasgupta and Mäler (2000), Dasgupta (2001a), and Arrow et al. (2003a,b). For a more complete account of the theory, see Dasgupta (2008b). But the idea that movements in wealth should be the basis on which "sustainable development” is discussed had been aired informally for several years earlier. See Serageldin (1995) and Pearce et al. (1996). 


$$
\Delta V(t)=[\partial V / \partial t] \Delta t+{ }_{i} \Sigma\left[\partial V / \partial K_{i}(t)\right] \Delta K_{i}(t) .
$$

As $p_{i}(t)=\partial V(t) / \partial K_{i}(t)$, equation (2) can be written as

$$
\Delta V(t)=[\partial V / \partial t] \Delta t+{ }_{i} \Sigma p_{i}(t) \Delta K_{i}(t) \cdot \mathrm{QED}
$$

Equation (1) and Proposition 1 suggest that comprehensive wealth (or wealth, for short) is a measure of the economy's productive base. Moreover, Proposition 1 says that the reason we should be interested in that particular measure of the productive base is that it moves in unison with social well-being. Equation (3) is even stronger than Proposition 1 . The equation says that if an economy is perturbed slightly, the change in social well-being accompanying the perturbation equals the change in wealth (at constant shadow prices) that is caused by it.

Now $p_{\mathrm{i}}(t) \Delta K_{\mathrm{i}}(t)$ is the shadow value of net investment in asset $i$, and $\partial V / \partial t$ is the shadow price of time $t\left(r(t)\right.$ in expression (1)). Write $I_{i}(t)=p_{\mathrm{i}}(t) \Delta K_{\mathrm{i}}(t)$. Then equation (3) can be expressed as

$$
\Delta V(t)=[\partial V / \partial t] \Delta t+{ }_{i} \Sigma\left[I_{i}(t)\right]
$$

Definition 2 says that the expression on the right hand side of equation (4) is the comprehensive investment that accompanies the perturbation. This means Proposition 1 can be re-stated as

Proposition 2: A small perturbation to an economy increases (resp., decreases) social wellbeing at $t$ if, and only if, the comprehensive investment at $t$ that accompanies the perturbation is positive (resp. negative). ${ }^{20}$

Proposition 1 explains why (comprehensive) wealth is the correct measure of social well-being and why it ought to replace GDP, HDI, and the many other ad hoc measures that are currently taken to reflect social well-being. As wealth is a linear index of the stocks of the economy's (comprehensive) list of capital assets, while social well-being is a non-linear function of its determinants (as in various forms of Utilitarianism, see Appendix), it is a far more convenient index to use for responding to questions (B) to (E) than social well-being itself.

We could imagine that the typical perturbation considered in Propositions 1-2 involves positive investments in some assets (e.g. roads and building, education and health), but negative investments in other assets (e.g., wetlands and forests). Proposition 2 says that so long as comprehensive investment is positive, social well-being increases. Note though that if certain ecological assets were to become very scarce, their shadow prices would be large, signalling that further declines in their amounts, even when small, would make a significant dent on comprehensive investment.

20 It may seem odd to regard the first term in equation (4) as investment, since no one is doing anything other than wait to see the corresponding asset grow. As waiting is a cost, it seems to me there is nothing wrong in including $[\partial V / \partial t] \Delta t$ in our conception of comprehensive investment.

There is no settled term yet for the linear index we are calling "comprehensive investment” here. I am borrowing the term from Arrow et al. (2007), but it has been called "genuine saving” (World Bank, 2006), and also "inclusive investment" (Dasgupta, 2007). I am hoping that the term "comprehensive investment" will prevail, because it is vivid. 


\subsection{The Welfare Significance of Net Domestic Product}

Propositions 1-3 also explain why net domestic product (NDP) isn't a measure of social wellbeing. To see why, consider a closed economy. Suppose there are M consumption goods and services (they are all flows), labelled ${ }_{j}$. Let $C_{j}(t)$ be the consumption of ${ }_{j}$ at $t$ and $q_{j}(t)$ its shadow price (Appendix: eq. (A.4)). Write NDP at $t$ as NDP( $t$ ). Using equation (2), we have

$$
N D P(t)={ }_{j} \Sigma q_{j}(t) C_{j}(t)+[\partial V / \partial t] \Delta t+{ }_{i} \Sigma\left[p_{i}(t) \Delta K_{i}(t)\right],
$$

which can be re-expressed as

$$
N D P(t){ }_{j} \Sigma q_{j}(t) C_{j}(t)=[\partial V / \partial t] \Delta t+{ }_{i} \Sigma\left[p_{i}(t) \Delta K_{i}(t)\right]
$$

Proposition 2 and equation (5) together yield

Proposition 3: A small perturbation to an economy increases (resp., decreases) social well-being at $t$ if, and only if, aggregate consumption is less than (resp. greater than) net domestic product.

Proposition 3 uncovers the welfare content of NDP. In a classic work, Lindahl (1933) used what amounts to the obverse of Proposition 3 to define "income" as the maximum consumption that an economy can enjoy without reducing its wealth. But in recent years economists have wanted to claim a lot more for net domestic product. They have wanted to prove that NDP is proportional to social well-being. ${ }^{21}$ But it can be shown that $\mathrm{NDP}(\mathrm{t})$ moves in unison with $\mathrm{V}(\mathrm{t})$ if, and only if, the conception of social well-being that is being adopted is wholly insensitive to inequality among people, generations, and uncertain contingencies (Dasgupta and Mäler, 1991; Dasgupta, 2008b).

Earlier we distinguished a perturbation at a point in time from a perturbation that amounts to the passage of time itself. That distinction tells us that Propositions 1 and 2 can be interpreted in two ways. We study them in the following two sections.

\section{Comprehensive Investment and Sustainable Development}

Consider first the passage of time along an economic forecast. The forecast could be, say, "business as usual".

\subsection{The Basic Theory}

Proposition 1 says that the Brundtland Commission's notion of "sustainable development" is equivalent to "sustainable social well-being". For completeness let us define sustainable development in terms of the latter notion.

Definition 3. An economy enjoys sustainable development at $t$ if $d V(t) / d t \geq 0$.

Propositions 1 and 2 give us an ethical underpinning to the concept of "sustainable development" in the sense of the Brundtland Commission. They also provide an operational handle on the concept. On using Proposition 2 and Definition 3, we have

21 See Weitzman (1976) and an enormous literature that has followed that publication (for references, see Dasgupta, 2008b). 
Proposition 4. An economy enjoys sustainable development at $t$ if and only if comprehensive investment at $t$ is non-negative.

Notice that Propositions 1-4 are equivalence results. On their own they can't tell whether an economy is enjoying sustainable development at a point in time. It could be that owing to bad policy choices in the past, the economy is experiencing unsustainable development even though sustainable development would have been possible had better policies been chosen. Worse still, if substitution possibilities between, say, certain vital ecological assets and other assets are limited and ecological capital has been drawn down ominously owing to past profligacy, it could be that sustainable development simply isn't feasible. ${ }^{22}$

Propositions 1-4 also say why GDP, NDP, HDI, and other ad hoc measures of social well-being won't do. It is certainly possible for an economy's productive base (i.e., wealth) to grow while GDP, say, increases, which is no doubt a path of economic development we all would like to follow. But it is also possible for an economy's productive base to shrink during a period when GDP (or even NDP) grows. ${ }^{23}$ The problem is that no one would notice the shrinking if everyone's eyes were riveted to GDP. If the economy's productive base continues to shrink, economic growth sooner or later stops and reverses sign. GDP will then decline, as will the standard of living, but no one would suspect that a fall was in store. So, growth in GDP per head can encourage us to think that all is well, when it isn't. In that regard, the Human Development Index, or HDI, is no better: it is possible for a country's HDI to increase even while its productive base shrinks. This means that HDI too can mislead (for illustrations based on international data, see Section 10.3).

Propositions 1, 2, and 4 also imply that the huge empirical literature on the factors influencing economic growth, admirably surveyed by Barro (1997), Helpman (2004), and Acemoglu et al. (2005), misdirects. The equations that define cross-country growth regressions have GDP growth on the left hand side. Proposition 1, on the other hand, says that GDP growth should be replaced by growth in comprehensive wealth. We should want to know for example, whether, other things being equal, political and civil liberties, economic and legal institutions, or trade liberalization or any one of the many other features of economies people take interest in promote the accumulation of comprehensive wealth. But for one work, currently in progress (Aidt, 2009), no one would appear to have studied such questions empirically. That there is even today no published study on the subject is no doubt because there are no reliable cross-country estimates of comprehensive wealth. But then there is no reason for any one to create such statistics if economists don't ask for them. And they will certainly not ask for them if they continue not to take natural capital seriously.

The one exception is Aidt (2009) who, in a work-in-progress on a large cross section of countries, has found that indictors of both perceived and actual corruption are negatively correlated with growth in comprehensive wealth per capita. The correlation would appear to be stronger and more robust than the correlation between corruption and GDP growth that has been reported by growth economists (e.g. Mauro, 1995). Aidt's estimates suggest that corrupt countries have been running down their wealth.

22 Proposition 3 would in this case be saying that it isn't feasible to maintain comprehensive wealth and at the same time enjoy positive aggregate consumption.

23 That both are theoretically possible is easy to demonstrate, so I leave it to the reader. Dasgupta (2001a, 2007) and Arrow et al. (2008) illustrated those possibilities using crude data from contemporary national accounts. I report a version of their findings below. 
That said, a higher growth rate in even comprehensive wealth isn't necessarily socially more desirable. A society's objective should be to promote the optimum growth in wealth.

If we are to put Propositions 1,2, and 4 to work on data, we need to find simple formulae for the various shadow prices. In earlier sections I reported on a small recent literature which offers estimates of the shadow prices of a number of natural capital assets. Here we look briefly at simple formulae for the shadow price of time.

Begin with the contribution the "residual" makes to comprehensive investment. In their empirical work on sustainable development, Arrow et al. (2004, 2008) constructed a simple formula for that contribution. $\delta v / \delta t$ was shown to be proportional to the residual. The authors estimated the contribution of the residual on the basis of the countries' macroeconomic data.

Turning to population growth, it could seem intuitive that in place of wealth the correct measure of social well-being is wealth per capita. In fact that intuition is generally speaking wrong. Dasgupta (2001a) proved that wealth per capita is the correct index only if (a) social well-being takes the form of what may be called "dynamic average utilitarianism" (see Appendix), (b) population grows (or declines) at a constant rate, and (c) each of the equations that represents an economy's accumulation process can be expressed in terms solely of per capita capital stocks. Formally if conditions (a)-(c) are satisfied, we have

Proposition 5. An economy enjoys sustainable development at $t$ if, and only if, at constant shadow prices (comprehensive) wealth per capita does not decline at t.

\subsection{Global Public Goods}

What of public goods? Let $\mathrm{G}(\mathrm{t})$ be the stock of a global public good at $\mathrm{t}$, to be interpreted here as carbon concentration in the atmosphere. $\mathrm{G}$ is an argument in the V-function of every country. Let $K_{m}(t)$ be the vector of assets owned by residents of country $m$. If $V_{m}$ is social well-being in $m$, we have,

$$
V_{m}(t)=V_{m}\left(\underline{K}_{m}(t), G(t), t\right)
$$

As before, let $\underline{p}_{m}(t)$ be the vector of shadow prices of all the assets owned by residents of $m$, and $g_{m}(t)=\partial V_{m}(t) / \partial G(t)$. We noted earlier that $G$ may well be an economic "good" for countries in the temperate zone and an economic "bad" in the tropics. For the former, $g_{m}>0$; for the latter, $g_{m}$ $>0$. Let $E_{m}(t)$ be the net emission rate from country $m$ and $E(t)$, the net aggregate emission. It follows that

$$
d G(t) / d t={ }_{m} \Sigma\left(E_{m}(t)\right)=E(t) .
$$

In order to focus on the accumulation of G, write

$$
I_{m}(t)={ }_{i} \Sigma p_{i}(t) d K_{i}(t) / d t .
$$

Using equation (7), equation (4) generalizes to

$$
d V_{m}(t) / d t=\partial V_{m} / \partial t+I_{m}(t)+g_{m}(t) d G(t) / d t .
$$

On using equation (6), equation (8) becomes

$$
d V_{m}(t) / d t=\partial V_{m} / \partial t+I_{m}(t)+g_{m}(t)\left[{ }_{m} \Sigma\left(E_{m}(t)\right)\right]
$$


We see next that recent empirical work on sustainable development has made use of Proposition 5. But when valuing climate change, not all authors have made use of equation (9).

\subsection{An Application}

Hamilton and Clemens (1999) and World Bank (2006) estimated comprehensive investment in the period 1970-2000 in over 120 countries. The authors added crude estimates of investment in human capital to official estimates of investment in reproducible capital. They then subtracted disinvestments in natural capital from that sum. For investment in human capital, the authors used expenditures on education as proxy. To quantify disinvestments in natural capital, they considered changes in the stocks of commercial forests, oil and minerals, and the concentration of carbon dioxide in the atmosphere. Oil and minerals were valued at their market price minus extraction costs. Forests were valued in terms of their market price minus logging costs. Contributions of forests to ecosystem functions were ignored.

In placing a value to increases in carbon concentration, Hamilton and Clemens (1999) and World Bank (2006) made a curious move. They took the shadow price of global carbon concentration to be $-\$ 20$ per ton $\left({ }_{\mathrm{m}} \sum \mathrm{g}_{\mathrm{m}}(t)\right.$ in our notation) and multiplied that figure to the carbon emission rate of a country to arrive at the damage the country suffers from an increase in carbon concentration. To put it formally, "net benefit" to country $m$ from emissions was identified as $\left[{ }_{\mathrm{m}} \sum \mathrm{g}_{\mathrm{m}}(t)\right] E_{m}(t)$, whereas, as equation (9) shows, the correct formula is $g_{m}(t)\left[{ }_{\mathrm{m}} \sum E_{\mathrm{m}}(t)\right]$. The two expressions are equal only under very special circumstances (e.g., if countries are identical).

Arrow et al. (2008) have interpreted ${ }_{\mathrm{m}} \sum\left(g_{\mathrm{m}}(t)\right)$ as the global shadow price of carbon in the atmosphere (-\$20 per ton). Using the estimates in Mendelssohn et al. (2006), they arrived at a figure for $g_{m}(t)$ for country $m$ by calculating the share of the global damage to $m$ and multiplying $g_{m}(t)$ by the global emission rate ${ }_{\mathrm{m}} \Sigma E_{\mathrm{m}}(t)$. In constructing the first column of figures in Table 1 , I have followed that procedure.

The list of natural resources in Hamilton and Clemens (1999) was very incomplete. It didn't include water resources, fisheries, air and water pollutants, soil, and other ecosystems. On the other side of the ledger the authors' notion of human capital was inadequate. Health didn't enter the calculus, even though life expectancy increased in most poor countries. Moreover, Hamilton and Clemens had nothing to say about growth in population, nor changes in total factor productivity. In other words, their exercise didn't come close to an analysis of sustainable development in the contemporary world, where population growth has been large and total factor productivity growth has been non-negligible. Furthermore, their estimates of shadow prices were very crude. Nevertheless, one has to start somewhere, and their attempt was a bold, first pass at what is proving to be an enormously difficult research programme.

In Dasgupta (2001a) I adapted the Hamilton-Clemens estimates for South Asia, sub-Saharan Africa, and China, by taking into account population growth and public investment in education. The theoretical basis of my estimates was Proposition 5. But I ignored TFP growth in those economies because I didn't know how to determine the shadow price of the "residual". Arrow et al. (2004) adapted the estimates in Dasgupta (2001a) by including the residual. They then went on to ask whether economic development in South Asia, sub-Saharan Africa, and China has been sustainable in recent decades. Table 1 is a refinement of that publication. It remains a very crude beginning to the study of sustainable development, but again, it's a start. 
The places in question are sub-Saharan Africa, Bangladesh, India, Nepal, and Pakistan (all poor countries) and China (a middle income country). The period under study is 1970-2000. The first column of numbers in Table 1 consists of refinements of the estimates of Hamilton and Clemens of comprehensive investment as a proportion of GDP. I have changed their figures by adding crude estimates of public expenditures on health and education and by estimating the "disinvestment" that corresponds to the increase in carbon concentration $\left(g_{m}(t)\left[{ }_{\mathrm{m}} \Sigma E_{\mathrm{m}}(t)\right]\right.$ for each $\left.m\right)$.

The figures in the second column are average annual population growth rates during the period and those in the third column are estimates of annual growth rates of total factor productivity (TFP), which we interpret here as the annual percentage rate of change in a combined index of knowledge and institutions. In order apply Proposition 5, I have divided the figures in the first column by the ratio of GDP to (comprehensive) wealth (the figures for which are explained below). To them I have simply added the estimates of TFP growth. That computation gives us an approximation to the (percentage) rates of change of (comprehensive) wealth at constant shadow prices. If I now subtract the growth rates in population from them, I arrive at estimates of the annual rate of change in wealth per capita. Those estimates are given in the fourth column.

In national income statistics, capital-output ratios are typically in the region 4-5 years. In our numerical computation, however, "capital" should be meant to read the shadow value of all capital assets excepting for time (Arrow et al., 2008). We therefore expect capital-GDP ratios to be greater than 4-5 years. Arrow et al. (2008) estimated that capital-GDP ratio in China is in the region 10-12 years, most probably it is even higher. In Table 1, which should be taken to be purely illustrative of the kind of empirical investigation in sustainable development that lies ahead of us, I have assumed the capital-GDP ratio to be 10 years.

Before summarizing the findings, it will be useful to get a feel for what Table 1 is telling us. Consider Pakistan. During 1970-2000 comprehensive investment as a proportion of GDP was $8.8 \%$. TFP increased at an annual rate of $0.4 \%$. As both numbers are positive, Pakistan's productive base was larger in year 2000 than it had been in 1970. But take a look at Pakistan's population, which grew at $2.7 \%$ rate annually. The fourth column shows that Pakistan's per capita wealth declined in consequence, at an annual rate of 1.4\%, implying that in year 2000 the average Pakistani was a lot poorer than in 1970.

Interestingly, if we were to judge Pakistan's economic performance in terms of growth in GDP per capita, we would obtain a different picture. As the fifth column of Table 1 shows, Pakistan grew at a respectable $2.2 \%$ rate a year. If we now look at the sixth column, we find that the United Nations' Human Development Index (HDI) for Pakistan improved during the period. Movements in GDP per capita and HDI tell us nothing about sustainable development.

The striking message of Table 1 is that during 1970-2000 economic development in all the countries on our list other than China (which was a poor country during much of the period under study) was negative. To be sure, sub-Saharan Africa offers no surprise. Comprehensive investment was negative, implying that the region disinvested in reproducible capital, human capital, and natural capital, taken together, at an annual rate of 2.1\% of GDP. Population grew at 2.7\% a year and TFP barely advanced (annual growth rate: $0.1 \%$ ). Even without performing any calculation, we should suspect that the productive base per capita in sub-Saharan Africa declined. The table confirms that it did, at 2.8\% each year. If we now look at the fifth column of numbers, we discover that GDP per capita in sub-Saharan Africa remained pretty much constant. But the 
region's HDI showed an improvement - confirming once again that studying movements in HDI enables us to say nothing about sustainable development.

What accounts for the striking difference between movements in GDP and wealth during 19702000 ? There are two factors at work. First, the investment ratios in the first column of numbers in Table 1 are comprehensive investment ratios, and they are lower in each country than the recorded investment ratio. Secondly, and more importantly, the capital-output ratio I have used to convert figures in the first column of numbers is 10 years, not the $4-5$ years that appear in national statistics.

Table 1 shows that Pakistan is the worst performer in the Indian sub-continent. But the remaining countries in the region also didn't make it. Comprehensive investment in each country (Bangladesh, India, and Nepal) was positive, as was growth in TFP. The two together imply that the productive base expanded there. But population growth was sufficiently high to more than neutralize growth in comprehensive wealth.

Comprehensive investment in China was $22.7 \%$ of GDP, which is a large figure. The residual was a high 3.6\% annually. Population grew at a relatively low rate: $1.4 \%$ per year. We shouldn't be surprised that China's wealth per capita expanded - as it happens, at an annual rate of approximately 4.5\%. Per capita GDP also grew at an annual rate of 7.8\%, and HDI improved. In China, GDP per capita, HDI, and wealth per head moved parallel to one another.

The figures we have just studied are all very rough and ready, but they show how accounting for natural capital can make a substantial difference to our conception of the development process. We should remember that the figures for several shadow prices I used to arrive at Table 1 are conservative. For example, a price of \$20 per ton of carbon in the atmosphere is almost certainly a good deal below its true global social cost. On the other hand, Table 1 underestimates improvements in human capital, at least for India and China. If, instead of using expenditure on health as proxy, we were to value increases in life expectancy in terms of the value of a statistical life, comprehensive investment in those countries would be a lot higher. Nevertheless, with all the above caveats (and more!) in mind, the message we should take away is sobering.

It would be wrong though to think that people in poor countries should have invested more by consuming less. In poor countries the production and distribution of goods and services are highly inefficient, implying that consumption and comprehensive investment there do not compete for a fixed quantity of funds. Better institutions would enable people in the poor world to both consume more and invest more - comprehensively, of course!.

\section{Evaluating Policy Reforms}

Studying sustainable development requires that we compare an economy's wealth as it moves through time. Evaluating policy reforms requires that we estimate the welfare effects of perturbations to an economy at a point in time. Imagine that at date t the government considers making a small change to existing policies. The perturbation could be adjustments to the prevailing structure of taxes, it could be alterations to the existing system of property rights, or it could be a small conservation project. Call any such perturbation a policy reform. The government needs a criterion by which to judge whether the reform is socially desirable. As the perturbation is to be introduced at t, we have $\Delta t=0$ in equations (3) and (4), which therefore reduce, respectively, to 


$$
\Delta V(t)={ }_{i} \Sigma\left[I_{i}(t)\right],
$$

and

$$
\Delta V(t)={ }_{i} \Sigma\left[p_{i}(t) \Delta K_{i}(t)\right]
$$

Obviously, if the reform is not marginal, equations (10) and (11) would be invalid. The traditional method of estimating $\Delta V(t)$ in such a case, which dates back to Dupuit's work in the nineteenth century, is to estimate the social surplus generated by the reform and add that surplus to the right hand side of equation (11). An alternative method would be to estimate an "average" of the shadow prices that prevailed before the reform and those that would prevail if the reform were put in place, and then value changes in the capital assets at those prices. Formally the method is to apply the "mean value theorem". Writing by $\mathrm{p}_{\mathrm{i}}^{*}(\mathrm{t})$ the "average" shadow price of asset $i$, we have

$$
\Delta V(t)={ }_{i} \Sigma\left[p_{i}^{*}(t) \Delta K_{i}(t)\right]
$$

\subsection{Social Cost-Benefit Analysis}

For concreteness we now interpret a "policy reform" to be a project. Equations (10)-(11) say that a project's (comprehensive) investment measures its contribution to social well-being. So we have

Proposition 6. A project should be accepted if and only if it would increase (comprehensive) wealth.

Proposition 6 says that wealth is the criterion we should use for project evaluation. So project evaluation and the economics of sustainable development involve the same welfare criterion: wealth. ${ }^{24}$

Call the flow of social well-being social felicity. Social well-being is most commonly taken to be the sum of the (discounted) flow of social felicity (equation (13) below). Frequently it is assumed too that felicity is a function solely of the flow of consumption (equation (13)). Under those assumptions Proposition 5 can be restated as

Proposition 7. Comprehensive investment measures the present discounted value of the resulting changes in consumption.

Proof: See Appendix.

Proposition 7 is familiar. It is also the basis for social cost-benefit analysis, for we have

Proposition 8. The criterion that should be used to evaluate projects socially is the present discounted value of the flow of the project's shadow profits.

Together, Propositions 6 and 8 can be combined as

Proposition 9. The present discounted value of a project's (net) profits equals its contribution to the economy's (comprehensive) wealth.

${ }_{24}$ In Dasgupta (2001b) I have more fully developed the role comprehensive wealth plays as a unified criterion in both sustainability analysis and policy evaluation. 
I am unable to say who first proved Proposition 7. It is implicit in Ramsey (1928), who studied an economy at the full optimum. Marglin (1963) proved the proposition for a simple imperfect economy and used it to develop a theory of social cost-benefit analysis (Dasgupta et al., 1972). Our formulation here shows that Propositions 6-9 are very general, covering as they do any kind of institutional imperfection. The Propositions form the welfare basis for responding to questions (D) and (E).

\subsection{Evaluating Projects in Practice}

Modern social cost-benefit analysis was developed for water resource management (Eckstein, 1958; Brown and McGuire, 1967). What drew the attention of development practitioners to the subject, however, was Little and Mirrlees $(1968,1974)$, who developed a methodology for use in poor countries. Although the Little-Mirrlees method was meant for imperfect economies, the imperfections it admitted were of a limited, structured kind. Dasgupta et al. (1972) formulated a method for social cost-benefit analysis that is applicable to a wider range of imperfect economies. ${ }^{25}$ Neither publication, however, had a word to say about ecological capital.

Over the years a number of economists have developed the theory of policy evaluation so as to be applicable to environmental projects in poor countries (e.g., Dasgupta, 1982, 2001a; Hufschmidt et al., 1983; Andersen, 1987; Newcombe, 1989; Duraiappah, 1997; Sterner, 2003). Even so, there are very few case studies, and it is worth exploring why.

Although the theory of project evaluation was much discussed within international development agencies following the publications by Little and Mirrlees (see, for example, Squire and Van der Taak, 1975), the subject appears to have been dropped there in the early 1980s. As I understand it, even the World Bank abandoned social cost-benefit analysis. ${ }^{26}$ And I can't recall ever reading the annual Human Development Report of the United Nations Development Programme in which a policy that was promoted by its authors had been subjected to serious economic evaluation. Elimination of extreme poverty has been the stated goal among international development agencies in recent years, but it would appear to be believed that the goal can be realized without the help of evaluation.

Those who have taken the logic of social cost-benefit analysis seriously aren't the only ones who have complained. Proponents of "random experiments" as a method for evaluating the effectiveness of policy reforms in poor countries have complained too (e.g., Duflo and Kremer, 2005). However, social cost-benefit analysis, in the sense in which I am using the term here, is a different species of evaluation technique from randomized trials. The latter identifies the welfare impacts of a well-defined programme, which should be interpreted as a policy reform. Randomized experiments would seem to be most suited to programmes that target individuals or local communities in education, health, and sanitation. Kremer and Miguel (2006), for example, is an illuminating exercise. The investigators conducted randomized experiments on a Kenyan programme involving the de-worming of intestinal parasites. They found that there is no realistic alternative to large long term external subsidies on de-worming drugs. For example, charging a small fee for de-worming drugs reduced the demand for treatment by $80 \%$. Intensive school health education intervention had no effect on worm prevention behaviour. It would seem that the private value on de-worming is very low in Kenya.

25 See Dasgupta (1972) for an account of the similarities and differences between the two methods.

26 Little and Mirrlees (1991) have speculated why. 
The strengths and limitations of random experiments as a policy evaluation tool were brought out in a classic paper by Heckman (1992). In the context of environmental projects, it should be assumed that randomized experiments will have been conducted by ecologists in order to determine the response ecosystems make to disturbances (e.g., the toxicity of chemicals in water systems). We take it that feasibility reports of environmental projects are based on, among other pieces of information, the findings of such experiments. When a report arrives on a government decisionmaker's desk, however, her job is to evaluate it, period.

It has been said that social cost-benefit analysis is too difficult in practice. Estimating shadow prices is no easy matter. Future uncertainties abound and influence shadow prices. One way to work round that problem is to conduct sensitivity analysis, by varying parameter values in projects and evaluating the project variants. Often the best the evaluator can do is to offer a spread of recommendations: "Accept the project if the range of parameter values is $\mathrm{R}$, reject it if the range is outside it" (see Dasgupta et al., 1972).

One way to make social cost-benefit analysis routine would be to conduct retrospective studies. One imagines that the World Bank, for example, has in store a large pool of project reports. A comparison could be made between a project's eventual performance and the expectations that had led to its acceptance. It has been said, for example, that infrastructure costs are almost invariably underestimated at the planning stage. If the claim is true, systematic cost overruns could be used to raise projected costs in current project evaluation. Ecological capital can be subjected to the same kind of exercise.

Duflo and Pande (2007) is an example of the value of retrospective evaluation. The authors studied the economic effects of large scale irrigation dams in India. They found that while downstream districts gained (agricultural productivity increased and volatility in productivity declined), the districts where the dams were built enjoyed only a negligible increase in agricultural productivity even while they experienced a rise in volatility. The latter group could therefore be regarded as having become poorer. That should be useful information when dams are proposed in the future.

If policies are to be evaluated, there is no escaping social cost-benefit analysis. No doubt methodological corners have to be cut in practice, but anchoring evaluation exercises to theory forces practitioners to make clear what corners are being cut. That is good discipline. Ad hoc evaluation procedures, usually developed to suit the case in hand, can often be nothing more than a reflection of the evaluator's prior beliefs about the merits of the case. They may even reflect the evaluator's political prejudices.

Project evaluation, for example, is a way to determine whether restoring ecological capital is better than installing substitute forms of capital. In a well known study Chichilnisky and Heal (1998) compared the costs of restoring the Catskill Watershed in New York State, whose ecological function in the past had been among other things to purify water, to the costs of building a water-purification plant, which would have been 8 billion US dollars. The authors showed the overwhelming economic advantages of restoration over construction. Independent of the many other services the Catskill watershed provides and ignoring the annual running costs of 300 million US dollars for a filtration plant, the capital costs alone showed a more than 6-fold advantage for investing in the ecosystem. 
The Chichilniski-Heal study took the social objective (the supply of purified water to New York City) as given. They sought to identify the cost-effective way to achieve an incontrovertible objective. Project evaluation more generally compares the costs with the benefits in order to determine whether a project should be accepted. Perhaps for those reasons evaluation of ecological projects continues to be rare. Of the most comprehensive case studies I have come across, two were among the earliest in print, while the other pair is of recent vintage.

In a pioneering monograph on a pair of a-forestation projects in northern Nigeria, Andersen (1987) studied the contributions shelterbelts and farm trees, respectively, make to both household and farm productivity - by supplying building material, fuel-wood, fruit, and fodder; and preserving soil and retaining moisture. The internal rate of return on investment in shelter-beds was found to be $15 \%$; the corresponding figure for farm trees was $19 \%$. It is hard to imagine that social discount rates would be anywhere as high as those figures. We should conclude that both were socially profitable projects.

In an equally interesting exercise, Newcombe (1989) found that population pressure had led to rural deforestation in the regions of Debre Zeit and Debre Berhan, Ethiopia. Subsistence farmers had therefore turned to dung as a source of household fuel. Newcombe showed that a-forestation would enable farmers to switch to wood-fuel as a source of household energy, thereby releasing dung for use as fertilizer. He estimated that the rates of return on such investment were in the astonishingly high range 35-70\%, depending on assumptions made on fuel-wood yield and the productivity of dung in agriculture.

Kakujaha-Matundu and Perrings (2000) contains an exceptional cost-benefit analysis of the relative social merits of livestock and wildlife in the Nyae Nyae rangeland of Namibia. Livestock offer meat and milk to herders, while wildlife attracts tourists. The rate of return on livestock herding was found to be $10 \%$ a year, that on wildlife conservation about $14.5 \%$. The authors showed that if the rangeland were to be optimally partitioned into the two activities, $70 \%$ of Nyae Nyae would be committed to wildlife conservation. Earlier, we noted that a PES system could be instituted to provide incentives to the inhabitants of the Nyae Nyae region to conserve wildlife.

The other study, by Whittington et al. (2008), evaluates alternative methods for clean water to households. The authors observe that the traditional method in rich countries involves centralized water supply sources and wastewater treatment facilities, combined with comprehensive pipe networks for water distribution and sewage collection. But they go on to show that this method may not be the most cost effective in poor countries. They do that first by evaluating a project in rural Africa that invests in the construction of deep boreholes with public hand pumps. The benefits that are considered include reductions in the incidence of diarrhoea. At social discount rates of 3-6\% a year the project's social profitability was found to be high (the benefit-cost ratio was approximately 3).

Whittington et al. (2008) also evaluate a community-led campaign in Bangladesh to free localities of open defecation. Among the costs is the construction of communal latrines. The authors recognise that the facilities would no be used if they are found to be inconvenient. Even so, at social discount rates of 3-6\%, the benefit-cost ratios of the programme were found to range from 2.4 to 7.5 depending on the sites chosen. The moral is important: in designing the supply of household water and sanitation facilities, the context matters. 


\section{Discounting Climate Change}

Perhaps the most vigorous application of social cost-benefit analysis in recent years has been to the economics of climate change. Prominent examples are Cline (1992), Nordhaus (1994, 2008) and Stern (2006). That Cline and Stern reached a very different conclusion on the optimal timing of global efforts to curb climate change from the one reached by Nordhaus was noted and discussed in Dasgupta (2007b) and Nordhaus (2007). As intergenerational ethics lies at the heart of the welfare economics of climate change, it is useful to review the issues.

\subsection{Global Activism Now or Later?}

The current concentration of carbon dioxide in the atmosphere is 385 parts per million (ppm). We are to imagine that there is a world goverment that can enforce whatever action is required to implement a world optimum. Suppose the global objective is to limit concentration to $500 \mathrm{ppm}$. Cline and Stern argued that the world should spend substantial sums starting today (Stern's figure amounts to $2 \%$ of the GDP of rich nations). Nordhaus $(1994,2008)$ in contrast has argued that it would be more equitable and efficient to invest in reproducible capital and human capital now so as to build up the productive base of economies - including, especially, poor countries. He has proposed an upward sloping climate policy ramp of ever tightening reductions in carbon emissions over the years. ${ }^{27}$

The difference between the two recommendations can be traced to differences in the authors' conceptions of intergenerational equity. We confirm below that as global warming involves the long run (100 years and more), economic evaluation of climate policies is sensitive to the choice of social discount rates.

The numeraire in social cost-benefit analysis is typically a determinant of social felicity. Most commonly the chosen determinant is aggregate consumption (or income) per head. We continue to assume a deterministic world. As before $V(t)$ denote social well-being at $t$ and let $U(t)$ be social felicity per capita at $t$. If $c(t)$ is consumption per head, all three authors assume $U(t)=$ $U(c(t))$. The present value shadow price of $c(t)$ is called the social discount factor. The social discount rate at $t$, which we write as $p(t)$, is defined as the percentage rate of decline in the social discount factor. Suppose by way of illustration (but see Appendix) that social well-being at $t=0$ is

$$
V(0)=\int_{0}^{\infty}\left[U(c(t)) e^{-\delta t}\right] d t, \quad \text { where } \delta \geq 0
$$

Until Section 12.4 we are to interpret $c$ as per capita world consumption and $V(0)$ in equation (13) as global well-being. Assume that the integral in expression (13) exists. In the Appendix we confirm that in consumption numeraire the social discount factor at $t$ is $[d U(c(t)) / d c(t)] e^{-\delta}$. Let $\alpha(c(t))$ be the elasticity of marginal felicity. As is well known, social aversion to consumption inequality among individuals requires that $\alpha(c(t))>0$. I follow the three authors by assuming that

27 See also Schelling (1999). The Nordhaus-Schelling prescription is widely misconstrued. How can they be so callous, it is asked, as to recommend a policy that could lead to a submersion of the (currently) densely populated coastal region of Bangladesh? In fact their thesis recommends Bangladesh to grow in wealth so as to enable coastal inhabitants to migrate and find employment elsewhere in the country. This may not be a realistic nor aesthetically appealing prescription, but it isn’t ethically repugnant. 
$\alpha$ is independent of $c(t)$. Write the percentage rate of change in $c(t)$ as $g(c(t))$. A simple calculation shows that

$$
\rho(t)=\delta+\alpha g(c(t))
$$

\subsection{Negative Discount Rates}

We confirm below that Cline, Nordhaus, and Stern have assumed that $\alpha \geq 1$. From equation (14), we note that if $g(c(t))$ is forecast to be positive, $p(t)$ is positive. Notice though that if $g(c(t))$ is forecast to be negative and $\delta$ is small, then $p(t)$ is negative. To illustrate, suppose $\delta=0$, $\eta=2$, and $g\left(C_{t}\right)=-1 \%$ per year. Then equation (14) says $\mathrm{p}_{t}=-2 \%$ per year. $I$ have colleagues in the US who find illustrations involving negative economic growth to be unrealistic. Recall though from Table 1 that sub-Saharan Africa suffered from negative growth during 1970-2000. What discount rates should government project evaluators there have chosen in 1970 if they had an approximately correct forecast of the shape of things to come?

That negative growth rates in consumption can imply negative social rates discount rates is significant because people in the tropics are likely to suffer greatly from climate change under business as usual. Moreover, the possibility of negative growth in consumption takes an interesting turn when we come to consider uncertainty in future consumption (see Section 12.4).

\subsection{The Welfare Economics of Climate Change}

The most-preferred values of $\delta$ and $\alpha$ in Cline (1992), Nordhaus (1994) and Stern (2006), respectively, were as follows:

Cline: $\delta=0 ; \alpha=1.5$

Nordhaus: $\delta=3 \%$ a year; $\alpha=1$

Stern: $\delta=0.1 \%$ a year; $\alpha=1$

Notice the closeness between the parameter values assumed by Cline and Stern. That explains why their recommendations on the timing of expenditure on climate change were very similar. Unfortunately, despite the closeness, there was no reference to Cline's work in the version of Stern (2006) that was circulated prior to publication. And there was only a perfunctory reference to Cline in Stern (2006) and no mention that their recommendations were similar. The custom of having texts screened by independent referees was designed more than three centuries ago to prevent such acts of omission. Priority should matter.

The point estimate of $g(c(t))$ under business as usual in Stern (2006) was 1.3\% a year. Using this figure in equation (14) yields

$$
\begin{aligned}
& p(t)=2.05 \% \text { a year for Cline } \\
& p(t)=4.30 \% \text { a year for Nordhaus } \\
& p(t)=1.40 \% \text { a year for Stern }
\end{aligned}
$$

$4.3 \%$ a year may not seem very different from $1.4 \%$ a year, but is in fact a lot higher when put to work on the economics of the long run. Just how much higher can be seen from the fact that the present-value of a given loss in consumption, owing, say, to climate change 100 years from now, if discounted at $4.3 \%$ a year is seventeen times smaller than the present-value of that same consumption loss if the discount rate used is $1.4 \%$ a year. The moral is banal: If the time horizon is long, even small differences in social discount rates can mean large differences in the message 
cost-benefit analysis gives us. The difference between the prescriptions in Cline (1992) and Stern (2006), on the one hand, and Nordhaus (1994), on the other, have little to do with differences in the climate models the authors worked with, they have all to do with differences in the way the authors interpret intergenerational equity. Nordhaus (2007) confirms that by using Stern's specifications for $\delta$ and $\alpha$ in the climate-change model he has developed over the past two decades. It should be noted that in our numerical illustration, Nordhaus' choice of $p(t)=4.30 \%$ a year would be consistent with the US government's discount rate policy (on the latter, see Viscusi, 2007).

In a recent book Nordhaus (2008) has chosen a figure of $4 \%$ a year to discount changes in future consumption. He has justified the figure on grounds that it is approximately the long run risk-free interest rate in the US, which amounts to the claim that the risk-free rate is the social rate of return on investment.

I have not understood the underlying logic. The social discount rate on consumption equals the social rate of return on investment in a fully optimum economy. But $4 \%$ a year is an observed figure in a world riddled with the externalities carbon emissions give rise to. The atmosphere is even now more or less an open access global common. For all we know the social rate of return on certain forms of investment (e.g., carbon intensive investment) today is negative. Over three decades ago Brock (1977) noted relatedly that the marginal product of private capital would be biased upward in a market economy due to an overuse of nature's inputs. His argument was that the marginal product of capital increases with nature's inputs and that the latter are underpriced. Of course, it is legitimate to select investment as numeraire and base the justification of $4 \%$ a year on that choice. But if one selects investment as numeraire in an imperfect economy, consumption must be re-valued at its shadow price (Marglin, 1963; Dasgupta et al., 1972; Little and Mirrlees, 1974). Nordhaus doesn't do that revaluation.

It should be a requirement of any exercise in social cost-benefit analysis that it be subjected to sensitivity tests. In the economics of climate change, alternative climate scenarios, taken from publications of the Intergovernmental Panel for Climate Change (IPCC) have featured prominently. But social cost-benefit analysis involves the use of "value" parameters too. In the formulation adopted by Cline, Nordhaus, and Stern, the value parameters are $\delta$ and $\alpha$. Curiously, Stern (2006) contains no simulation in which $\delta$ and $\alpha$ were made to assume alternative numerical values. It is almost as though the values Stern chose came from Government House. But that's hardly the way to do welfare economics. We have little prior intuition of what $\delta$ and $\alpha$ imply in elaborate models of global climate change, which is all the more reason why project evaluation should include alternative figures for value parameters.

It has been argued by philosophers that, leaving aside the possibility of collective extinction, $\delta$ should be taken to be zero (Rawls, 1972; Broome, 1992). On the other hand, Koopmans $(1960,1972)$ proved that a set of intuitively appealing ethical axioms on infinite felicity streams, when taken together, demand that $\delta$ should be positive. In Dasgupta (2008c) I put $\delta$ and $\alpha$ to a test by calculating the optimum rate of consumption in a classroom model of consumption and capital accumulation. Assuming $\delta=0.1 \%$ a year and the rate of return on investment to be $4 \%$ a year (which is an altogether very generous figure), I found that if $\alpha=1$, the optimum saving rate is over 95\% of GDP. But a 95\% saving rate is an absurdly heavy burden on the present generation, in a world where future generations will be increasingly rich owing to the productivity of capital. The calculation suggested, at least to me, that $\alpha=1$ reflects an ethics that is insensitive to intergenerational inequality. 


\subsection{Social Aversions to Inequality and Risk}

Larger values of $\alpha$ suggest themselves, in the range 1.5 to 3 (see the exercises in Dasgupta, 2008c). As $\alpha$ is a measure of inequality aversion, larger values would recommend lower rates of saving in a deterministic world. That would lessen the burden on the current generation. But the future is uncertain. If social well-being under uncertainty is taken to be the expectation of the present discounted value of the sum of social felicities, $\alpha$ is a measure of risk aversion as well. It can be shown that if $\alpha>1$, uncertainty in the rate of return on investment is a reason for saving more for the future (Levhari and Srinivasan, 1969). The message is awkward: as $\alpha$ has a dual role in intergenerational ethics, it creates a tension between two opposing considerations.

Let $c^{\sim}(t)$ be the uncertain consumption level per head at $t$. For mathematical tractibility, I assume now that time is discrete $(t=0,1, \ldots)$. Equation (14) says that if $\mathrm{E}$ is the expectation operator, expected social well-being can be written as

$$
E[V(0)]=E\left\{{ }_{0} \Sigma^{\infty}\left[U(\widetilde{c}(t)) /(1+\delta)^{\prime}\right]\right\}, \quad \delta \geq 0 .
$$

Pesaran et al. (2007) and Weitzman (2007) have shown that if uncertainty over future consumption possibilities is determined econometrically from past observations, it will have a "thick" lower tail (e.g. a power function), implying that there is a positive chance of consumption dropping as close to zero as you could fear. Weitzman gave colour to his analysis by alluding to "catastrophic" events that could come in the wake of climate change. The authors showed that if $\alpha \geq 1$, and the horizon is infinite, and the uncertainty has a thick lower tail, the precautionary motive for saving becomes so great as to render the concept of intergenerational justice embodied in equation (15) incoherent. Formally, the integral in equation (15) diverges and social cost-benefit analysis becomes meaningless.

The matter is worse, in that a much stronger result has been known for years. Dasgupta (2008c) used the model of capital accumulation in Levhari and Srinivasan (1969) to show that if $\alpha \geq 1$ and the horizon is infinite and the uncertainty in future consumption possibilities is "large" relative to other parameters, expression (15) doesn't converge even if the probability distribution over $c(t)$ at each date is "thin" tailed, as in the case of the log normal distribution.

How disturbed should we be by this result? Not much, or so it seems to me. The most recent publications of IPCC contain only a finite number of scenarios, none of which considers it to be even a remote possibility that consumption will decline to zero. Moreover, a major artificiality in the models studied by Cline, Nordhaus and Stern is the assumption that $\alpha \geq 1$. Many years ago Arrow (1965) offered reasons as to why we should work with felicity functions that are bounded at both ends. He argued in favour of U-functions for which $\alpha(c)$ increases monotonically from values less than one to values greater than one. If we invoke such felicity functions, the paradox of infinity generated by large risks would not occur. ${ }^{28}$

28 There are two other assumptions underlying expression (15) that are surely artifacts: the constant hazard rate (ä) for humanity's extinction and an infinite horizon. One way to ensure that the ethical framework we invoke doesn't have contradictions no matter how large the uncertainty would be to to abandon the infinite time horizon. But the choice of a terminal date would at best be arbitrary. That is why economists have avoided working with finite time horizon models.

Another possible way out would be to continue to postulate an infinite time horizon, but formalize humanity's extinction process in terms of a hazard rate that increases in an unbounded fashion over time at a sufficiently high rate. The problem is that we have little intuition on how to formulate that in a way that is scientifically reasonable. 
Global project evaluation should involve the use of a more disaggregated version of social wellbeing than expression (15). Let $c_{p}$ and $c_{r}$, respectively, be average consumption in the poor and rich worlds. And let $N_{p}$ and $N_{r}$ be their respective population sizes. An appealing extension of expression (15) would be

$$
\left.V(0)=E\left\{\sum_{0} \Sigma^{\infty}\left[L_{p}(t) U\left(\tilde{c}_{p}(t)\right)+L_{r}(t) U\left(\tilde{c}_{p}(t)\right)\right] /(1+\delta)^{\prime}\right]\right\}, \quad \delta \geq 0 .
$$

If $\alpha$ is taken to be constant in expression (16), it takes on three roles. It is a measure of inequality aversion among contemporaries, across the generations, and across uncertain contingencies. And that may be too much for a single parameter to do adequately. Which is also why nonconstant $\alpha$ 's suggest themselves.

\subsection{Climate Treaties}

Maximizing expression (13) (more so, expression (16)) presumes an enlightened world government. So, the social cost-benefit analysis reported in, for example, Stern (2006) is a pure abstraction. In the absence of an overarching authority we can at best hope for agreements among nations that are self-enforcing. Anthropogenic climate change involves reciprocal externalities (Section 6), which is why the formation of coalitions in the face of reciprocal externalities and the policies that are likely to emerge on the basis of international negotiations has received much attention over the years (Barrett, 1994, 2003; Carraro, 2002; Finus and Runshagen, 2003; Uzawa, 2003; Carraro and Fragnelli, 2004; Dutta and Radner, 2004, are among the prominent contributions). By "self-enforcing", one means an agreement with the property that if a party expects those others who have signed the agreement to abide by it, then it is in the interest of that party to abide by it too; that is, the agreement is a Nash equilibrium. In negotiations over climate change, the parties are countries. Barrett $(1994,2003)$ and Dutta and Radner (2004), among others, have argued that the Kyoto Protocol didn't lay the groundwork for a self-enforcing treaty. They used that to explain why the Protocol has been a disappointment.

As countries differ in size, wealth, and location, Nash equilibrium is not unique. Among equilibrium outcomes is the "null-treaty", meaning global non-cooperation, commonly referred to as "business as usual". Treaties would however differ in their efficiency and in the distribution of benefits and burdens. It is a feature of equilibrium outcomes that not all countries would be party to potential treaties; some (among them some small countries) would free ride. Among the choices to be made in designing a treaty are adaptation and mitigation measures. The costs and benefits involving the two kinds of investment would be expected to differ among countries. So, economists who study the political economy of climate change face the problem of having to explain which equilibrium would be selected. Factors outside theoretical models would be particularly relevant here. The power of rich countries could be expected to tilt the selection toward their favour.

In an interesting and important paper, Barrett (2008) observes that although it is frequently claimed that adaptation and mitigation are complements, they are more like substitutes. As countries invest more in the former, they suffer less from climate change and find mitigation less attractive. But mitigation is a global public good ("windmills"), whereas adaptation is a national public good ("dikes"). One can imagine a situation where the globally optimal investment policy obtained from maximizing expression (16) would have every country invest in windmills, but where the non-cooperative equilibrium is one where each country constructs only dikes. Imagine that the ideal treaty (with appropriate, credible side payments) sustains a high level of participation and 
requires so many windmills to be built that no one needs to construct dikes. Barrett constructs examples where, nevertheless, the treaties that are signed are ones under which rich countries construct dikes and pollute the atmosphere, leaving poor countries not so much high and dry, as "low and wet". Such an ominous possibility cannot yet be ruled out.

\section{Conclusions}

In this paper I have reviewed what seems to me to be the most salient issues in ecological economics when the subject is applied to the field of economic development. My aim here has not been to be scholastic but to examine the lives of the world's poor so as to unearth the role of natural capital there. I will have succeeded if the account here of the processes that characterise human-nature interactions reads differently from the accounts in recent surveys of both development economics and environmental and resource economics.

I began with the micro-foundations of rural institutions in poor regions and offered a picture of rural poverty in terms of household access to the local natural-resource base. The findings documented bring to date those I reported in Dasgupta (1993). This article is a natural extension of the earlier work and has advanced very much the same viewpoint as that did about the processes that shape world poverty.

The concept of sustainable development was explored in a macroeconomic setting and an empirical study was conducted on the character of economic development in the world's poorest regions in the last quarter of the previous century. Natural capital was for the most part seen as "private" goods, in the sense of not being jointly consumable. In the final section there was a discussion of global climate as a "public" good.

What can we conclude from our analysis? It seems to me the following should be noted:

(1) The socio-ecological processes that shape extreme poverty in the world's poor regions run at different speeds and operate at different spatial scales. Disasters occur frequently in the poor world, but unlike famines, civil wars, and hurricanes, their occurrence is localised and confined to small groups. That is why it is easy to overlook them.

(2) The externalities that the use of ecological capital gives rise to are not confined to market failure, they are expressions of institutional failure in its widest sense: failure at the international level, the level of the state, of communities, of households. The locus of failure depends, among other things, on the ecological capital in question. The cause of eutrophication of a village pond in West Bengal is very different from the cause of dead zones in the Gulf of Mexico.

(3) We should be circumspect about market-friendly solutions to environmental problems. Externality markets are inevitably thin, meaning that without a sympathetic involvement of the state, the elite would be expected to enjoy the spoils from ecological services.

(4) The protection and promotion of ecological capital is encouraged in systems where payment is made to owners for the ecological services provided by their capital assets. Whether payment for ecosystem services should be made by the beneficiaries or the state depends on the context.

(5) The persistence of rural poverty is tied both to the fragile state of the local natural-resource 
base and the rate of population growth. But the causality isn't unidirectional. Each variable would be endogenous in any model that speaks to human-nature interchanges.

(6) Both economic theory and empirical studies have shown that devolution of management powers over the local natural-resource base is, generally speaking, good for the environment and good for poverty alleviation. But as elsewhere in economics, mixed systems work best. Textbook states would ensure that the local elite don't take a disproportionate amount from the commons. Where the state is weak or corrupt, NGOs can play a major role in keeping the state at bay and the elite from enjoying the bulk of the services from nature.

(7) As a macroeconomic statistics of social well-being, GDP per capita is singularly bad. So is the United Nations Human Development Index (HDI). Among other shortcomings, GDP per head and HDI ignore depreciation of capital. The deficiency can be alarming in the world we live in (Table 1).

(8) The statistic that moves in unison with social well-being (by the latter we mean an aggregate of the well-beings of the present and all future generations) is a comprehensive measure of wealth, which is the social worth of an economy's entire stock of capital assets, including not only reproducible capital, human capital, and knowledge and institutions, but also natural capital.

(9) Comprehensive wealth (or wealth for short) can be used both for evaluation exercises and for assessing whether development has been (or is forecast to be) sustainable.

(10) Although there are still only a few rigorous studies in social cost-benefit analysis of environmental projects, the message we should take away from them is that projects that protect and promote natural capital can be socially very profitable.

(11) The relative appeal of alternative policies toward mitigating or adapting to climate change is sensitive to the choice of social discount rates. As we still have little intuitive understanding of parameters reflecting ethical values, evaluation exercises should contain sensitivity analysis.

(12) Statistics (albeit very crude) suggest that in the final quarter of the twentieth century South Asia and sub-Saharan Africa experienced a decline in wealth per head, even though South Asia enjoyed positive growth in GDP per head and improvements in HDI, while sub-Saharan Africa enjoyed an improvement in HDI but experienced a small decline in GDP per head. The data suggest that China in contrast followed a path of sustainable development. It bears emphasis though that the empirical exercise involving Table 1 is so crude and incomplete that the Chinese data misrepresent the situation there. Despite the caveats, the moral is that the macroeconomic history of nations looks very different when nature is included as a capital asset in economic activity.

(13) The problem of climate change as faced by poor countries can only be addressed at the collective level of nations. But case studies suggest that so far the environmental problems the rural poor face have been caused by institutional failure at the national and community levels. The composition of commodity demands from rich countries can certainly veer poor countries toward unsustainable resource use. But poor countries usually have choices. Moreover, there is enough inefficiency in poor countries to enable governments there to identify policies that both protect and promote natural capital and alleviate poverty. The idea that the poor world can enjoy sustainable 
development only when there are significant improvement in the international economic architecture is belied by evidence on village life in poor countries.

The overarching moral that emerges from the studies I have presented here may appear banal, but is salutary:

Development policies that ignore our reliance on ecological capital are seriously harmful - they don't pass the mildest test for equity among contemporaries, nor among people separated by time and uncertain contingencies.

\section{Acknowledgements}

In preparing this article I have drawn on my Yan Fu Memorial Lecture at Peking University, 2005; Bingham Lecture at the Research Triangle Institute (Durham, NC), 2006; the Annual Distinguished Speakers Lecture at the Asian Development Bank (Manila), 2007; the Wrigley Lecture at Arizona State University (Tempe), 2007; and the John Kenneth Galbraith Lecture at the American Agricultural Economics Association Annual Conference (Portland, Oregon), 2007. My understanding of ecological and development economics has been much influenced over the years by discussions with Toke Aidt, Kenneth Arrow, Scott Barrett, William (“Buzz”) Brock, William Clark, Gretchen Daily, Anantha Duraiappah, Paul Ehrlich, Kirk Hamilton, Rashid Hassan, Sriya Iyer, Robert Kates, Pramila Krishnan, Karl-Göran Mäler, Pranab Mukhopadhyay, Subhrendu Pattanayak, Charles Perrings, Robert Scholes, Ismail Serageldin, Priya Shyamsundar, V. Kerry Smith, E. Somanathan, Jeff Vincent, and the many scholars associated with the Beijer Institute of Ecological Economics and the South Asian Network for Development and Environmental Economics (SANDEE), who are too numerous to name individually. In preparing this paper I have benefited enormously from the editorial comments of Dani Rodrik. 


\section{References}

Acemoglu, D., S. Johnson, and J.A. Robinson (2005), "Institutions as a Fundamental Cause of Long-Run Growth”, in P. Aghion and S.N. Durlauf, eds., Handbook of Economic Growth, Vol. 1A (Amsterdam: North Holland).

Acharya, G. (2000), “Approaches to Valuing the Hidden Hydrological Services of Wetland Ecosystems”, Ecological Economics, 35(1), 63-74.

Acharya, G. and E.B. Barbier (2000), "Valuing Ground Water Recharge Through Agricultural Production in the Hadejia' Jama' are Wetlands in Northern Nigeria”, Agricultural Economics, 22, 247-259.

Agarwal, A. and S. Narain (1989), Towards Green Villages: A Strategy for Environmentally Sound and Participatory Rural Development (New Delhi: Centre for Science and Development).

Agarwal, A. and S. Narain (1996), Dying Wisdom: Rise, Fall and Potential of India's Traditional Water Harvesting Systems (New Delhi: Centre for Science and Development).

Agarwal, B. (2001), "Participatory Exclusions, Community Forestry, and Gender: An Analysis for South Asia and a Conceptual Framework”, World Development, 29(10), 1623-1648.

Aggarwal, R., S. Netanyahu, and C. Romano (2001), “Access to Natural Resources and the Fertility Decision of Women: The Case of South Africa”, Environment and Development Economics, 6(2), 209-236.

Aghion, P. and S. Durlauf eds. (2005), Handbook of Growth Economics, Vols. $1 A$ \& 1B (Amsterdam: North Holland).

Aidt, T. (2009), “Corruption, Institutions, and Development”, Oxford Review of Economic Policy, forthcoming 2009.

Anderson, D. (1987), The Economics of Afforestation: A Case Study in Africa (Baltimore: The Johns Hopkins University Press).

Aronsson, T., P.-O. Johansson, and K.-G. Lofgren (1997), Welfare Measurement, Sustainability and Green Accounting: A Growth Theoretic Approach (Cheltenham: Edward Elgar).

Arrow, K.J. (1965), Aspects of the Theory of Risk-Bearing (Helsinki: Yrjö Jahnssonin säätiö).

Arrow, K.J. (1971), "Political and Economic Evaluation of Social Effects of Externalities”, in M. Intriligator ed., Frontiers of Quantitative Economics, Vol. 1 (Amsterdam: North Holland).

Arrow, K.J., P. Dasgupta, and K.-G. Mäler (2003a), "Evaluating Projects and Assessing Sustainable Development in Imperfect Economies”, Environmental \& Resource Economics, 26(4), 647-685. 
Arrow, K.J., P. Dasgupta, and K.-G. Mäler (2003b), “The Genuine Savings Criterion and the Value of Population”, Economic Theory, 21(2), 217-225.

Arrow, K.J., P. Dasgupta, L. Goulder, G. Daily, P.R. Ehrlich, G.M. Heal, S. Levin, K.-G. Mäler, S. Schneider, D.A. Starrett, and B. Walker (2004), “Are We Consuming Too Much?”, Journal of Economic Perspectives, 18(1), 147-172.

Arrow, K.J., P. Dasgupta, L.H. Goulder, K. Mumford, and K. Oleson (2008), Untitled, in preparation.

Arrow, K.J. and M. Kurz (1970), Public Investment, the Rate of Return and Optimal Fiscal Policy (Baltimore: Johns Hopkins University Press).

Atkinson, A.B. and J.E. Stiglitz (1980), Lectures in Public Economics (New York: McGraw Hill).

Baland, J.-M., P. Bardhan, and S. Bowles, eds. (2007), Inequality, Cooperation, and Environmental Sustainability (New York: Russell Sage Foundation).

Baland, J.-M. and J.-P. Platteau (1996), Halting Degradation of Natural Resources: Is There a Role for Rural Communities? (Oxford: Clarendon Press).

Baland, J.-M. and J.-P. Platteau (1999), “Inequality and Collective Action in the Commons”, World Development, 27(5), 773-788.

Baland, J.-.M., P. Bardhan, and S. Bowles, eds. (2007), Inequality, Cooperation, and Environmental Sustainability (New York: Russell Sage Foundation).

Balasubramanian, R. (2008), "Community Tanks vs Private Wells: Coping Strategies and Sustainability Issues in South India”, in R. Ghate, N.S. Jodha, and P. Mukhopadhyay (2008), Promise, Trust and Evolution: Managing the Commons of South Asia (Oxford: Oxford University Press).

Bandopadhyay, S. and P. Shyamsundar (2004), "Fuelwood Consumption and Participation in Community Forestery in India”, Policy Research Working Paper 3331, World Bank, Washington, DC.

Bandopadhyay, S., P. Shyamsundar, and K.R. Kanel (2006), "Forestery User Groups in Nepal: Can Institutional Change Lead to Economic Development?”, Background Paper for the Nepal Poverty Assessment, World Bank, Washington, DC.

Banerjee, A.V. and E. Duflo (2005), "Growth Theory Through the Lens of Development Economics", in P. Aghion and S.N. Durlauf eds., Handbook of Economic Growth, Vol. $1 \mathrm{~A}$ (Amsterdam: Elsevier), 474-552.

Barbier, E.B. (1994), “Valuing Environmental Functions: Tropical Wetlands”, Land Economics, 70(2), 155-173. 
Barbier, E.B. (2000), "Valuing the Environment as an Input: Review of Mangroive-Fishery Linkages”, Ecological Economics, 35(1), 47-61.

Barbier, E.B. (2005), Natural Resources and Economic Development (Cambridge: Cambridge University Press).

Barbier, E.B. and I. Strand (1998), “Valuing Mangrove-Fishery Linkages: A Case Study of Campeche, Mexico”, Environmental and Resource Economics, 12(1), 51-66.

Bardhan, P. and J. Dayton-Johnson (2007), "Inequality an Governance of Water Resources in Mexico and South India”, in J.-M. Baland, P. Bardhan, and S. Bowles, eds., Inequality, Cooperation, and Environmental Sustainability (New York: Russell Sage Foundation).

Barrett, S. (1994), "Self-Enforcing International Environmental Agreements”, Oxford Economic Papers, 46(3), 878-894.

Barrett, S. (2003), Environment \& Statecraft: The Strategy of Environmental Treaty-Making (New York: Oxford University Press).

Barrett, S. (2008), “Dikes vs. Windmills: Climate Treatise and Adaptation”, Discussion Paper, The Johns Hopkins University.

Barro, R.J. (1997), Determinants of Economic Growth: A Cross-Country Empirical Study (Cambridge, MA: MIT Press).

Barro, R.J. and X. Sala-i-Martin (2003), Economic Growth (Cambridge, MA: MIT Press).

Baumol, W.M. and W. Oates (1975), The Theory of Environmental Policy (Englewood Cliffs, NJ: Prentice-Hall).

Beck, T. and C. Nesmith (2001), "Building on Poor People’s Capacities: The Case of Common Property Resources in India and West Africa”, World Development, 29(1), 119-133.

Beteille, A., ed. (1983), Equality and Inequality: Theory and Practice (Delhi: Oxford University Press).

Bhargava, A. (2008), Food, Economics, and Health (Oxford: Oxford University Press).

Bigg, G. (2003), The Oceans and Climate (Cambridge: Cambridge University Press), Second Edition.

Bin, O. and S. Polasky (2005), "Evidence on the Amenity Value of Wetlands in a Rural Setting”, Journal of Agricultural and Applied Economics, 37(3), 589-602.

Bledsoe, C. (1994), ““Children are Like Young Bamboo Trees’: Potentiality and Reproduction in sub-Saharan Africa,” in K. Lindahl-Kiessling and H. Landberg, eds., Population, Economic Development and the Environment (Oxford: Oxford University Press). 
Brauman, K.A., G.C. Daily, T. Ka’eo Duarte, and H.A. Mooney (2007), “The Nature and Value of Ecosystem Services: An Overview Highlighting Hydrological Services”, Annual Review of Environment and Resources, 32, 67-98.

Brock, W.A. (1977), “A Polluted Golden Age”, in V.L. Smith, ed., Economics of Natural and Environmental Resources (New York: Gordon and Breach).

Brock, W.A. and D.A. Starrett (2003), "Non-Convexities in Ecological Management Problems”, in P. Dasgupta and K.-G. Mäler, eds., The Economics of Non-Convex Ecosystems (Dordrecht: Kluwer Academic Publishers).

Bromley, D.W., ed. (1992), Making the Commons Work: Theory, Practice and Policy (San Francisco: ICS Press).

Broome, J. (1992), Counting the Cost of Global Warming (London: White Horse Press).

Brown, G. and C.B. McGuire (1967), “A Socially Optimal Pricing Policy for a Public Water Agency”, Water Resources Research, 3(1), 33-43.

Bulte, E.H., L. Lipper, R. Stringer, and D. Zilberman (2008), "Payments for Ecosytem Services and Poverty Reduction: Concepts, Issues, and Empirical Perspectives", Environment and Development Economics, 13(3), 245-254.

Campbell, B., A. Manando, N. Nemarundwe, B. Sithole, W. De Jong, M. Luckert, and F. Matose (2001), "Challenges to Proponents of Common Property Resource Systems: Despairing Voices from the Social Forests of Zimbabwe”, World Development, 29(4), 589-600.

Carpenter, S.R. (2001), “Alternate States of Ecosystems: Evidence and Its Implications”, in M.C. Press, N. Huntly, and S. Levin, eds., Ecology: Achievement and Challenge (London: Basil Blackwell, 2001).

Carpenter, S.R., D. Ludwig, and W.A. Brock (1999), "Management of Eutrophication for Lakes Subject to Potentially Irreversible Change”, Ecological Applications, 9(4), 751-71.

Carpenter, S.R., P.L. Pingali, E.M. Bennet, and M.B. Zurek, eds. (2005), Ecosystems and Human Well-Being, Vol. 2: Scenarios (Washington DC: Island Press).

Carraro, C. (2002), “Climate Change Policy: Models, Controversies, and Strategies”, in T. Tienteberg and H. Folmer, eds., The International Yearbook of Environmental and Resource Economics 2002/2003 (Cheltenham: Edward Elgar).

Carraro, C. and V. Fragnelli eds. (2004), Game Practice and the Environment (Cheltenham: Edward Elgar).

Carson, R.T. (2004), Contingent Valuation: A Comprehensive Bibliography and History (Northampton, MA (USA): Edward Elgar).

Cavendish, W. (2000), "Empirical Regularities in the Poverty-Environment Relationships of Rural Households: Evidence from Zimbabwe”, World Development, 28(11), 1979-2003. 
C.S.E. - Centre for Science and Environment - (1990), Human-Nature Interactions in a Central Himalayan Village: A Case Study of Village Bembru (New Delhi: Centre for Science and Environment).

Chichilnisky, G. (1994), "North-South Trade and the Global Environment”, American Economic Review, 84(3), 851-874.

Chichilnisky, G. and G.M. Heal (1998), “Economic Returns from the Biosphere”, Nature, 391, 629-630.

Chopra, K. and S.C. Gulati (1998), "Environmental Degradation, Property Rights and Population Movements: Hypotheses and Evidence from Rajasthan (India)”, Environment and Development Economics, 3(1), 35-57.

Chopra, K., G.K. Kadekodi and M.N. Murty (1989), Participatory Development: People and Common Property Resources (New Delhi: Sage Publications).

Cline, W.R. (1992), The Economics of Global Warming (Washington, DC: Institute for International Economics).

Coase, R. (1960), “The Problem of Social Cost”, Journal of Law and Economics, 3(1), 1-44.

Colchester, M. (1995), "Sustaining the Forests: The Community-Based Approach in South and South-East Asia”, Development and Change, 25(1), 69-100.

Collier, P. (2007), The Bottom Billion (Oxford: Oxford University Press).

Cooke, P., G. Kohlin, and W.F. Hyde (2008), "Fuelwood, Forests, and Community Management - Evidence from Household Studies”, Environment and Development Economics, 13(1), 103135.

Czako, Å. and E. Sik (1988), “Manager’s Reciprocal Transactions”, Connections, 11(1), 23-32.

Daily G., ed. (1997), Nature's Services: Societal Dependence on Natural Ecosystems (Washington, DC: Island Press).

Daily, G. and K. Ellison (2002), The New Economy of Nature: The Quest to Make Conservation Profitable (Washington, DC: Island Press).

Dasgupta, P. (1969), “On the Concept of Optimum Population”, Review of Economic Studies, 36(3), 295-318.

Dasgupta, P. (1972), “A Comparative Analysis of the UNIDO Guidelines and the OECD Manual”, Bulletin of the Oxford University Institute of Economics and Statistics, 34(1), 33-51.

Dasgupta, P. (1982), The Control of Resources (Cambridge, MA: Harvard University Press). Dasgupta, P. (1990), “The Environment as a Commodity”, Oxford Review of Economic Policy, 6(1), 51-67. 
Dasgupta, P. (1993), An Inquiry into Well-Being and Destitution (Oxford: Clarendon Press).

Dasgupta, P. (2000), “Economic Progress and the Idea of Social Capital”, in P. Dasgupta and I. Serageldin, eds., Social Capital: A Multifaceted Perspective (Washington, DC: World Bank), pp. 325-424.

Dasgupta, P. (2001a), Human Well-Being and the Natural Environment (Oxford: Oxford University Press), 2nd ed. (2004).

Dasgupta, P. (2001b), "Valuing Objects and Evaluating Policies in Imperfect Economies", Economic Journal, 111 (Conference Issue), 1-29.

Dasgupta, P. (2003), “Population, Poverty, and the Natural Environment”, in K.-G. Mäler and J. Vincent, eds, Handbook of Environmental and Resource Economics, Vol. 1 (Amsterdam: North Holland), pp. 191-247.

Dasgupta, P. (2004), "World Poverty: Causes and Pathways”, in F. Bourguignon and B. Pleskovic, eds., Annual World Bank Conference on Development Economics 2003: Accelerating Development (New York: World Bank and Oxford University Press), pp. 159-196.

Dasgupta, P. (2007a), Economics: A Very Short Introduction (Oxford: Oxford University Press).

Dasgupta, P. (2007b), “Comments on the Stern Review’s Economics of Climate Change”, National Institute Economic Review, 199, 4-7.

Dasgupta, P. (2008a), “Common Property Resources: Economic Analytics”, in R. Ghate, N.S. Jodha, and P. Mukhopadhyay, eds. (2008), Promise, Trust and Evolution: Managing the Commons of South Asia (Oxford: Oxford University Press).

Dasgupta, P. (2008b), “The Welfare Economic Theory of Green National Accounts”, Environmental and Resource Economics, forthcoming, 2008.

Dasgupta, P. (2008c), “Discounting Climate Change”, Journal of Risk and Uncertainty, forthcoming, 2008.

Dasgupta, P. and G. Heal (1979), Economic Theory and Exhaustible Resources (Cambridge: Cambridge University Press).

Dasgupta, P. and K.-G. Mäler (1991), “The Environment and Emerging Development Issues,” Proceedings of the Annual World Bank Conference on Development Economics 1990 (Washington, DC: World Bank), 101-132.

Dasgupta, P. and K.-G. Mäler (2000), “Net National Product, Wealth, and Social Well-Being”, Environment and Development Economics, 5(1), 69-93.

Dasgupta, P. and K.-G. Mäler, eds. (2003), The Economics of Non-Convex Ecosystems (Dordrecht: Kluwer Academic Publishers). 
Dasgupta, P., S. Marglin, and A. Sen (1972), Guidelines for Project Evaluation (New York: United Nations).

Dasgupta, P. and H. Sabourian (2008), "Bilateral Negotiations over Undirectional Externalities”, Mimeo., Faculty of Economics, University of Cambridge.

Diamond, J. (2005), Collapse: How Societies Choose to Fail or Survive (London: Allen Lane).

Dinar, A., R. Hassan, R. Mendelsohn, J. Benhin et al. (2008), Climate Change and Agriculture in Africa: Impact Assessment and Adaptation Strategies (London: Earthscan).

Dobson, A.P., A.D. Bradshaw, and A.J.M. Baker (1997), "Hope for the Future: Restoration Ecology and Conservation Biology”, Science, 277, 515-522.

Dreze, J. and A. Sen (1990), Hunger and Public Action (Oxford: Clarendon Press).

Dreze, J. and A. Sen (1995), India: Economic Development and Social Opportunities (Oxford: Oxford University Press).

Duflo, E. and M. Kremer (2005), "Use of Randomization in the Evaluation of Development Effectiveness”, in G. Pitman, O. Feinstein, and G. Ingram, eds., Development Effectiveness (New Brunswick, NJ: Transaction Publisher).

Duflo, E. and R. Pandey (2007), “Dams”, Quarterly Journal of Economics, 122(2), 601-646.

Duraiappah, A.K. (2003), Computational Models in the Economics of Environment and Development (Dordrecht: Kluwer).

Dutta, P.K. and R. Radner (2004), “Self-Enforcing Climate Change Treatise”, Proceedings of the National Academy of Sciences, 101(14), 5174-5179.

Eckstein, O. (1958), Water Resources Development: The Economics of Project Evaluation (Cambridge, MA: Harvard University Press).

Ehrlich, P.R. (2008), “Key Issues for Attention From Ecological Economists”, Environment and Development Economics, 13(1), 1-20.

Ehrlich, P.R. and A.H. Ehrlich (1981), Extinction: The Causes and Consequences of the Disappearance of Species (New York, NY: Random House).

Ehrlich, P.R. and A.H. Ehrlich (1990), The Population Explosion (New York: Simon and Schuster).

Ehrlich, P.R. and A.H. Ehrlich (2008), The Dominant Animal: Human Evolution and the Environment (Washington DC: Island Press).

Ehrlich, P.R., A.H. Ehrlich, and J.P. Holdren (1977), EcoScience: Population, Resources, Environment (San Francisco, CA: W.H. Freeman). 
Englin, J. and R. Mendelsohn (1991), “A Hedonic Travel Cost Analysis for Valuation of Multiple Components of Site Quality: The Recreation Value of Forest Management”, Journal of Environmental Economics and Management, 21(2), 275-290.

Ensminger, J. (1992), Making a Market: The Institutional Transformation of an African Society (New York: Cambridge University Press).

Falconer, J. (1990), The Major Significance of "Minor" Forest Products: the local use and value of forests in the West African humid forest zone (Rome: Food and Agriculture Organization).

Fankhauser, S. (1995), Valuing Climate Change: The Economics of Greenhouse (London: Earthscan).

Feeny, D., F. Berkes, B.J. McCay, and J.M. Acheson (1990), "The Tragedy of the Commons: Twenty-two Years Later”, Human Ecology, 18(1), 1-19.

Filmer, D. and L. Pritchett (2002), "Environmental Degradation and the Demand for Children: Searching for the Vicious Circle in Pakistan”, Environment and Development Economics, 7(1), 123-146.

Finus, M. and B. Rundshagen (2003), Endogenous Coalition Formation in Global Pollution Control: A Partition Function Approach”, in C. Carraro, ed. (2003), The Endogenous Formation of Economic Coalitions (Cheltenham: Edward Elgar).

Freeman III, A.M. (1993), The Measurement of Environmental and Resource Values: Theory and Methods (Washington, DC: Resources for the Future).

Ghate,R., N.S. Jodha, and P. Mukhopadhyay, eds. (2008), Promise, Trust and Evolution: Managing the Commons of South Asia (Oxford: Oxford University Press).

Goldstein, J., G.C. Daily, J.B. Friday, P.A. Matson, R.L. Naylor, and P.M. Vitousek (2006), "Business Strategies for Conservation on Private Lands: Koa Forestry as a Case Study", Proceedings of the National Academy of Sciences, 103(26), 10140-10145.

Gren, I.M., C. Folke, R.K. Turner, and I. Bateman (1994), "Primary and Secondary Values of Wetland Ecosystems”, Environmental and Resources Economics, 4(1), 55-74.

Guyer, J.L. (1994), "Lineal Identities and Lateral Networks: The Logic of Polyandrous Motherhood," in C. Bledsoe and G. Pison, eds., Nupitality in Sub-Saharan Africa: Contemporary Anthropological and Demographic Perspectives (Oxford: Clarendon Press).

Hamilton, K. and M. Clemens (1999), “Genuine Savings Rates in Developing Countries”, World Bank Economic Review, 13(2), 333-56.

Hartwick, J.M. (1990), “Natural Resources, National Accounting, and Economic Depreciation”, Journal of Public Economics, 43(3), 291-304.

Hartwick, J. (2000), National Accounting and Capital (Cheltenham: Edward Elgar). 
Hassan, R. ed. (2002), Accounting for Stock and Flow Values of Woody Land Resources (Pretoria: University of Pretoria).

Hassan, R., R. Scholes, and N. Ash, eds. 2005), Ecosystems and Human Well-Being, Vol. 1: State and Trends (Washington DC: Island Press).

Hecht, S., A.B. Anderson and P. May (1988), “The Subsidy from Nature: Shifting Cultivation, Successional Palm Forests and Rural Development”, Human Organization, 47(1), 25-35.

Heckman, J.J. (1992), “Randomization and Social Policy Evaluation”, in C. Manski and I. Garfinkel, eds., Evaluating Welfare and Training Programs (Cambridge, MA: Harvard University Press).

Helpman, E. (2004), The Mystery of Economic Growth (Cambridge, MA: Belknap).

Heyser, N. (1996), Gender, Population and Environment in the Context of Deforestation: A Malaysian Case Study (Geneva: United Nations Research Institute for Social Development).

Homer-Dixon, T.E. (1999), Environment, Scarcity, and Violence (Princeton, NJ: Princeton University Press).

Hufschmidt, M.M., D.E. James, A.D. Meister, B.T. Bower, and J.A. Dixon (1983), Environment, Natural Systems, and Development (Baltimore, MD: The Johns Hopkins University Press).

Isham, J., D. Narayan and L.H. Pritchett (1995), "Does Participation Improve Performance? Establishing Causality with Subjective Data”, World Bank Economic Review, 9(2), 175-200.

Jack, B.K., C. Kousky, and K.R.E. Sims (2008), “Designing Payment for Ecosystem Services: Lessons From Previous Experience with Incentive-Based Mechanisms”, Proceedings of the National Academy of Sciences, 105(28), 9465-9470.

Jalan, J. and E. Somanathan (2008), “The Importance of Being Informed: Experimental Evidence on Demand for Environmental Quality”, Journal of Development Economics, 87(1), 14-28.

Jodha, N.S. (1986), “Common Property Resources and the Rural Poor”, Economic and Political Weekly, 21, 1169-81.

Jodha, N.S. (2001), Living on the Edge: Sustaining Agriculture and Community Resources in Fragile Environments (Delhi: Oxford University Press).

Kadekodi, G.K. (2004), Common Property Resource Management: Reflections on Theory and the Indian Experience (Delhi: Oxford University Press).

Kim, E.H., A. Morse, and L. Zingales (2006), "What has Mattered to Economics Since 1970”, Journal of Economic Perspectives, 20(4), 189-202.

Kneese, A.V. and C.L. Schultze (1975), Pollution, Prices, and Public Policy (Washington, DC: Brookings Institution). 
Kolstad, C. (1999), Environmental Economics (New York: Oxford University Press).

Koopmans, T.C. (1960), “Stationary Ordinal Utility and Impatience,” Econometrica 28(2), 287-309.

Koopmans, T.C. (1965), “On the Concept of Optimal Economic Growth”, Pontificiae Academiae Scientiarum Scripta Varia, 28. Reprinted in The Econometric Approach to Development Planning, 1966 (Amsterdam: North Holland).

Koopmans, T.C. (1967), “Objectives, Constraints and Outcomes in Optimal Growth Models”, Econometrica, 35(1), 1-15.

Koopmans, T.C. (1972), “Representation of Preference Orderings over Time.” In C.B. McGuire and Roy Radner, eds., Decision and Organization (Amsterdam: North Holland).

Kremer, M. and E. Miguel (2006), “The Illusion of Sustainability”, Working Paper No. 091, Bureau for Research and Economic Analysis of Development, Cnter for International Development, Harvard University, Cambridge, MA.

Lange, G.-M., R. Hassan, and K. Hamilton (2003), Environmental Accounting in Action: Case Studies from South Africa (Cheltenham: Edward Elgar).

Leisinger, K.M., K.M. Schmidt, and R. Pandya-Loch (2002), Six Billion and Counting: Population and Food Security in the 21st Century (Washington, DC: International Food Policy Research Institute).

Lenton, T.M., H. Held, E. Kriegler, J.W. Hall, W. Lucht, S. Rahnstorf, and H.J. Schellnhuber (2008), "Tipping Elements in the Earth's Climate System”, Proceedings of the National Academy of Sciences, 105(6), 1786-1793.

Levhari, D. and T.N. Srinivasan (1969), “Optimal Savings Under Uncertainty,” Review of Economic Studies 36(2), 153-163.

Lindahl, E.R. (1933), “The Concept of Income”, in G. Bagge ed., Economic Essays in Honour of Gustav Cassel (London: Allen \& Unwin).

Lindahl, E.R. (1958), “Just Taxation - A Positive Solution”, in R.A. Musgrave and A.T. Peacock eds., Classics in the Theory of Public Finance (London: MacMillan). Translated from the original article in Swedish, published in 1919.

Little, I.M.D. and J.A. Mirrlees (1968), Manual of Industrial Project Analysis in Developing Countries: Social Cost Benefit Analysis (Paris: OECD).

Little, I.M.D. and J.A. Mirrlees (1974), Project Appraisal and Planning for Developing Countries (London: Heinemann).

Little, I.M.D. and J.A. Mirrlees (1991), “Project Appraisal and Planning Twenty Years On”, Proceedings of the Annual World Bank Conference on Development Economics 1990 (Washington, DC: World Bank), 351-382. 
Lopez, R. (1997), "Environmental Externalities in Traditional Agriculture and the Impact of Trade Liberalization: The Case of Ghana”, Journal of Development Economics, 53(1), 17-39.

Lopez, R. (1998), “The Tragedy of the Commons in Cote d'IvoireAgriculture: Empirical Evidence and Implications for Evaluating Trade Policies”, World Bank Economic Review, 12(1), 105132.

Lopez-Feldman, A. and J.E. Wilen (2008), "Poverty and Spatial Dimensions of Non-Timber Forest Extraction”, Environment and Development Economics, 13(5), 621-642.

Loughran, D. and L. Pritchett (1998), "Environmental Scarcity, Resource Collection, and the Demand for Children in Nepal”, Discussion Paper, World Bank, Washington, DC.

Lutz, E., ed. (1993), Toward Improved Accounting for the Environment (Washington, DC: World Bank).

Mäler, K.-G. (1974), Environmental Economics: A Theoretical Enquiry (Baltimore, MD: Johns Hopkins University Press).

Mäler, K.-G. (1991), “National Accounting and Environmental Resources”, Environmental and Resource Economics, 1(1), 1-15.

Mäler, K.-G. and R.E. Wyzga (1976), Economic Measurement of Environmental Damage (Paris: OECD).

Marglin, S.A. (1963), “The Opportunity Costs of Public Investment”, Quarterly Journal of Economics, 77(2), 274-289.

Mauro, P. (1995), “Corruption and Economic Growth”, Quarterly Journal of Economics, 110(3), 681-712.

McCulloch, N., A.A. Winters, and X. Cirera (2001), Trade Liberalization and Poverty: A Handbook (London: Department for International Development).

McKean, M. (1992), "Success on the Commons: A Comparative Examination of Institutions for Common Property Resource Management”, Journal of Theoretical Politics, 4(2), 256-68.

Meade, J.E. (1952), “External Economies and Diseconomies in a Competitive Situation”, Economic Journal, 62(1), 54-67.

Meade, J.E. (1955), Trade and Welfare (Oxford: Oxford University Press).

Meade, J.E. (1973), The Theory of Externalities (Geneva: Institute Universitaire de Hautes Etudes Internationales).

M.E.A. - Millennium Ecosystem Assessment - (2003), Ecosystems and Human Well-Being (Washington DC: Island Press). 
Mendelsohn, R., A. Dinar, and L. Williams (2006), “The Distributional Impact of Climate Change in Rich and Poor countries”, Environment and Development Economics, 11(2), 159-178.

Mirrlees, J.A. (1967), “Optimum Growth when Technology is Changing”, Review of Economic Studies, 34(1), 95-124.

Mirrlees, J.A. (1969), “The Evaluation of National Income in an Imperfect Economy”, Pakistan Development Review, 9(1), 1-13.

Mukhopadhyay, P. (2008), "Heterogeneity, Commons, and Privatization: Agrarian Institutional Change in Goa”, in R. Ghate, N.S. Jodha, and P. Mukhopadhyay, eds., (2008), Promise, Trust and Evolution: Managing the Commons of South Asia (Oxford: Oxford University Press)..

Myers, N. and J. Kent (2000), Perverse Subsidies: How Tax Dollars Undercut our Environment and Our Economies (Washington, DC: Island Press).

National Research Council (1986), Proceedings of a Conference on Common Property Resource Management (Washington, DC: National Academy Press).

National Research Council (2002), The Drama of the Commons (Washington, DC: National Academy Press).

Nerlove, M. (1991), "Population and the Environment: A Parable of Firewood and Other Tales”, American Journal of Agricultural Economics, 75(1), 59-71.

Netting, R. (1985), Hill Farmers of Nigeria: Cultural Ecology of the Kofyar of the Jos Plateau (Seattle: University of Washington Press).

Newcombe, K.J. (1989), “An Economic Justification of Rural Afforestation: The Case of Ethiopia”, in G. Schramm and J.J. Warford, eds., Environmental Management and Economic Development (Baltimore: The Johns Hopkins University Press).

Nordhaus, W.D. (1994). Managing the Global Commons: The Economics of Climate Change. Cambridge, MA: MIT Press.

Nordhaus, W.D. (2007), “The Stern Review on the Economics of Climate Change,” Journal of Economic Literature, 45(3), 686-702.

Nordhaus, W.D. (2008), A Question of Balance: Weighing the Options on Global Warming Policies (New Haven, CT: Yale University Press).

Nordhaus, W.D. and J. Tobin (1972), “Is Economic Growth Obsolete?”, in Economic Growth, 5th Anniversary Colloquium of the NBER (New York: Columbia University Press).

Noronha, R. (1997), “Common Property Resource Management in Traditional Societies”, in P. Dasgupta and K.-G. Mäler eds., The Environment and Emerging Development Issues (Oxford: Clarendon Press, 1997). 
North, D. and R.P. Thomas (1973), The Rise of the Western World: A New Economic History (Cambridge: Cambridge University Press).

Ostrom, E. (1990), Governing the Commons: The Evolution of Institutions for Collective Action (Cambridge: Cambridge University Press).

Ostrom, E. (1992), Crafting Institutions for Self-Governing Irrigation Systems (San Francisco, CA: International Center for Self-Governance Press).

Ostrom, E. (1996), "Incentives, Rules of the Game, and Development”, Proceedings of the Annual World Bank Conference on Development Economics, 1995 (Supplement to the World Bank Economic Review and the World Bank Research Observer), 207-234.

Pagiola, S., N. Landell-Mills, and J. Bishop (2002), “Making Market-Based Mechanisms Work for Forests and People”, in S. Pagiola, J. Bishop, and N. Landell-Mills, eds., Selling Forest Environmental Services: Market-Based Mechanisms for Conservation and Development (London: Earthscan).

Pagiola, S., A.R. Rios, and A. Arcenas (2008), "Can the Poor Participate in Payments for Environmental Services? Lessons from the Silvopastoral Project in Nicaragua”, Environment and Development Economics, 13(3), 299-326.

Palm, C.A., S.A. Vosti, P.A. Sanchez, and P.J. Erickson, eds., (2005), Slash-and-Burn Agriculture: The Search for Alternatives (New York: Columbia University Press).

Pattanayak, S.K. (2004), "Valuing Watershed Services: Concepts and Empirics from Southeast Asia”, Agriculture, Ecosystems \& Environment, 104(1), 171-184.

Pattanayak, S.K. and D.T. Butry (2005), "Spatial Complementarity of Forests and Farms: Accounting for Ecosystem Services”, American Journal of Agricultural Economics, 87(4), 995-1008.

Pattanayak, S.K. and R.A. Kramer (2001), "Worth of Watersheds: A Producer Surplus Approach for Valuing Drought Mitigation in Eastern Indonesia”, Environment and Development Economics, 6(1), 123-146.

Pattanayak, S.K. and E.O. Sills (2001), "Do Tropical Forests Provide Natural Insurance? The Microeconomics of Non-Timber Forest Collection in the Brazilian Amazon", Land Economics, 77(4), 595-612.

Pearce, D., W. Cline, A. Achanta, S. Fankhauser, R. Pachauri, R. Tol, and P. Vellinga (1996), "The Social Cost of Climate Change: Greenhouse Damage and the Benefits of Control”, in J. Bruce, H. Lee, and E. Haites, eds., Climate Change 1995: Economic and Social Dimensions of Climate Change (Cambridge: Cambridge University Press).

Pearce, D., K. Hamilton, and G. Atkinson (1996), “Measuring Sustainable Development: Progress on Indicators”, Environment and Development Economics, 1(1), 85-101. 
Perrings, C. (2000), “The Biodiversity Convention and Bio-Diversity Loss in sub-Saharan Africa”, in C. Perrings, ed. (2000), The Economics of Biodiversity Conservation in Sub-Saharan Africa (Cheltenham: Edward Elgar).

Perrings, C., ed. (2000), The Economics of Biodiversity Conservation in Sub-Saharan Africa (Cheltenham: Edward Elgar).

Perrings, C. and J.R. Vincent, eds. (2003), Natural Resource Accounting and Economic Development: Theory and Practice (Cheltenham: Edward Elgar).

Pesaran, H., D. Pettenuzzo, and A. Timmermann (2007), “Learning, Structural Instability, and Present Value Calculations,” Econometric Reviews 6(2-4), 253-88.

Pezzey, J.C.V. (1992), “Sustainable Development Concepts: An Economic Analysis”, World Bank Environment Paper No. 2, World Bank, Washington, DC.

Pezzey, J.C.V. and M.A. Toman (2002), "Progress and Problems in the Economics of Sustainability", in T. Tietenberg and H. Folmer, eds., The International Yearbook of Environmental and Resource Economics 2002/2003 (Cheltenham, UK: Edward Elgar).

Pigou, A.C. (1920), The Economics of Welfare (London: Macmillan).

Ramsey, F.P. (1928), “A Mathematical Theory of Saving”, Economic Journal, 38(4), 543549.

Rawls, J. (1972), A Theory of Justice (Oxford: Oxford University Press).

Ray D. (1998), Development Economics (Princeton, NJ: Princeton University Press).

Reid, W.V., H.A. Mooney, A. Cropper et al. (2005), Ecosystems and Human-Wellbeing: Synthesis (Wahington, DC: World Resources Institute).

Repetto, R. (1988), “Economic Policy Reform for Natural Resource Conservation”, Environment Department Working Paper No. 4, World Bank, Washington DC.

Repetto, R., R.C. Dower, R. Jenkins, and J. Geoghegan (1992), Green Fees: How a Tax Shift Can Work for the Environment and the Economy (Washington DC: World Resources Institute).

Repetto, R., W. Magrath, M. Wells, C. Beer, and F. Rossini (1989), Wasting Assets: Natural Resources and the National Income Accounts (Washington DC: World Resources Institute).

Ricketts, T.H., G.C. Daily, P.R. Ehrlich, and C. Michener (2004), "Economic Value of Tropical Forests in Coffee Production”, Proceedings of the National Academy of Sciences, 101, 1257912582.

Ricketts, T.H., J. Regetz, I. Steffan-Dewenter, S.A. Cunninghamd, C. Kremen, A. Bogdanski, B. Gemmill-Herren, S.S. Greenleaf, A.M. Klein, M.M. Mayfield, L.A. Morandin, A. Ochieng, and B.F. Viana (2008), "Landscape Effects on Crop Pollination Services: Are There General Patterns?”, Ecology Letters, 11, 499-515. 
Rosenzweig, C. and D. Hillel (1998), Climate Change and the Global Harvest: Potential Impacts of the Greenhouse Effect on Agriculture (New York: Oxford University Press).

Sachs, J.D. (2008), Common Wealth: Economics for a Crowded Planet (New York: Penguin Press).

Sachs, J.D., J.L. Gallup, and A. Mellinger (1998), “Geography and Economic Development”, in B. Pleskovic and J.E. Stiglitz, eds., Annual World Bank Conference on Development Economics (Washington DC: World Bank).

Schelling, T.C. (1999), “Intergenerational Discounting”, in P.R. Portney and J.P. Weyant, eds., Discounting and Intergenerational Equity (Washington DC: Resources for the Future).

Seabright, P. (1993), “Managing Local Commons: Theoretical Issues in Incentive Design”, Journal of Economic Perspectives, 7(1), 13-34.

Sekercioglu, C.H., C.G. Daily, and P.R. Ehrlich (2004), “Ecosystem Consequences of Bird Declines”, Proceedings of the National Academy of Sciences, 101(52), 18042-18047.

Sen, A. (1976), “Real National Income”, Review of Economic Studies, 43(1), 19-39.

Sen, A. (1999), Development as Freedom (Oxford: Oxford University Press).

Serageldin, I. (1995), “Are We Saving Enough for the Future?”, in Monitoring Environmental Progress, Report on Work in Progress, Environmentally Sustainable Development, World Bank, Washington, DC.

Shyamsundar, P. (2008), “Decentralization, Devolution, and Collective Action”, in R. Ghate, N.S. Jodha, and P. Mukhopadhyay, eds. (2008), Promise, Trust and Evolution: Managing the Commons of South Asia (Oxford: Oxford University Press).

Siebert, H. (2008), Economics of the Environment: Theory and Policy (Berlin: SpringerVerlag), 7th edition.

Smith, V.K. 91997), "Pricing What is Priceless: A Status Report on Non-Market Valuation of Environmental Resources”, in H. Folmer and T. Tietenberg, eds., The International Yearbook of Environmental and Resource Economics 1997/1998 (Cheltenham: Edward Elgar).

Smith, V.K. (2004), "Fifty Years of Contingent Valuation”, in T. Tietenberg and H. Folmer, eds., The International Yearbook of Environmental and Resource Economics 2004/2005 (Cheltenham: Edward Elgar).

Smith, V.K. and W.H. Desvousges (1987), “An Empirical Analysis of the Economic Value of Risk Changes”, Journal of Political Economy, 95(1), 89-114.

Solorzano, R., R. de Camino, R. Woodward, J. Tosi, V. Watson, A. Vasquez, C. Villalobos, J. Jimenez, R. Repetto, and W. Cruz (1991), Accounts Overdue: Natural Resource Depreciation in Costa Rica (Washington, DC: World Resources Institute). 
Somanathan, E. (1991), "Deforestation, Property Rights and Incentives in Central Himalaya”, Economic and Political Weekly, 26 (Special Issue: January 26) PE37-46.

Somanathan, E., R. Prabhakar, and B.S. Mehta (2005), “Does Decentralization Work? Forest Conservation in the Himalayas”, Discussion Paper 05-4, Indian Statistical Institute, Delhi.

Spence, A.M. (1974), “Blue Whales and Optimal Control Theory”, in H. Göttinger ed., Systems Approaches and Environmental Problems (Göttingen: Vandenhoek and Ruprecht).

Squire, L. and H. Van der Taak (1975), Economic Analysis of Projects (Baltimore: Johns Hopkins University Press).

Starrett, D.A. (1972), “Fundamental Non-Convexities in the Theory of Externalities”, Journal of Economic Theory, 4(1), 180-199.

Steffen, W., A. Sanderson, P.D. Tyson, J. Jäger, P.A. Matson, B. Moore III, F. Oldfield, K. Richardson, H.J. Schellnhuber, B.L. Turner II, and R.J. Wasson (2004), Global Change and the Earth System (Berlin: Springer).

Stern, N.H. (1989), “The Economics of Development: A Survey”, Economic Journal, 99(2), 597-685.

Stern, N.H. (2006). The Stern Review of the Economics of Climate Change (Cambridge: Cambridge University Press).

Sterner, T. (2003), Policy Instruments for Environmental and Natural Resource Management (Washington DC: Resources for the Future).

Stiglitz, J.E. (2002), Globalization and Its Discontents (New York: W.W. Norton).

Tallis, H., P. Kareiva, M. Marvier, and A. Chang (2008), “An Ecosystem Services Framework to Support both Practical Conservation and Economic Development," Proceedings of the National Academy of Sciences, 105(28), 9457-9464.

Thomson, J.T., D.H. Feeny, and R.J. Oakerson (1986), “Institutional Dynamics: The Evolution and Dissolution of Common Property Resource Management”, in National Research Council, Proceedings of a Conference on Common Property Resource Management (Washington, DC: US National Academy of Sciences).

Tilman, D., S. Polasky, and C. Lehman (2005), "Diversity, Productivity and Temporal Stability in the Economics of Humans and Nature", Journal of Environmental Economics and Management, 49(3), 405-426.

Tomich, T.P., M. van Noordwijk, and D.E. Thomas, eds. (2004), “Environmental Services and Land Use Change: Bridging the Gap between Policy and Research in Southeast Asia”, Ariculture Ecosystems \& Environment, Vol. 104, No. 1, (Amsterdam: Elsevier). 
Tomich, T.P., C.A. Palm, S.J. Velarde, H. Geist, A.N. Gillison, L. Lebel, M. Locatelli, W. Mala, M. van Noordwijk, K. Sebastian, D. Timmer, and D. White (2005), Forest and Agroecosystem Tradeoffs in the Humid Tropics (Nairobi: Alternatives to Slash-and-Burn Programme).

Turner, R.K., C.J.M. van den Bergh, T. Soderqvist, A. Barendregt, J. van der Straaten, E. Maltby, and E.C. Ireland (2000), "Ecological-Economics of Wetlands: Scientific Integration for Management and Policy, Ecological Economics, 35(1), 7-23.

Turner, R.K. and G.C. Daily (2008), “The Ecosystem Services Framework for Natural Capital Conservation”, Environment and Resource Economics, 39(1), 25-35.

UNDP - United Nations Development Programme - (2006, 2007/08), Human Development Report (New York: Oxford University Press).

Uzawa, H. (2003), Economic Theory and Global Warming (Cambridge: Cambridge University Press).

Vincent, J.R., R.M. Ali, and Associates (1997), Environment and Development in a ResourceRich Economy: Malaysia Under the New Economic Policy (Cambridge, MA: Harvard Institute for International Development).

Viscusi, W.K. (2007). “Rational Discounting for Regulatory Analysis,” University of Chicago Law Review 74(1), 209-246.

Viscusi, W.K. and J.E. Aldy (2003), "The Value of a Statistical Life: ACritical Review of Market Estimates Throughout the World”, The Journal of Risk and Uncertainty, 27(1), 5-76.

Vitousek, P.M., P.R. Ehrlich, A.H. Ehrlich, and P. Matson (1986), "Human Appropriation of the Product of Photosynthensis”, BioScience, 36, 368-373.

Vitousek, P.M., H.A. Mooney, J. Lubchenco, and J.M. Melillo (1997), "Human Domination of Earth’s Ecosystem”, Science, 277, 494-499.

Wade, R. (1988), Village Republics: Economic Conditions for Collective Action in South India (Cambridge: Cambridge University Press).

Weale, M. (1997), “Environment and National Accounts”, in P. Dasgupta and K.-G. Mäler, eds., The Environment and Emerging Development Issues, Vol. 1 (Oxford: Clarendon Press).

Weitzman, M.L. (1976), "On the Welfare Significance of National Product in a Dynamic Economy”, Quarterly Journal of Economics, 90(1), 156-162.

Weitzman, M.L. (2007), “The Role of Uncertainty in the Economics of Catastrophic Climate Change,” Discussion Paper, Department of Economics, Harvard University. Forthcoming, Review of Economics and Statistics.

Whittington, D., W.M. Hanemann, C. Sadoff, and M. Jeuland (2009), "Water and Sanitation Challenge Paper”, in B. Lomborg ed., Global Crises, Global Solutions, 2nd Ed. (Cambridge: Cambridge University Press). 
World Bank (2006), Where is the Wealth of Nations? (Washington, DC: World Bank).

World Commission on Environment and Development (1987), Our Common Future (New York: Oxford University Press).

World Resources Institute (2005), World Resources 2005: The Wealth of the Poor (Washington DC: World Resources Institute).

Zilberman, D., L. Lipper, and N. McCarthy (2008), "When Could Payments for Environmental Services Benefit the Poor?”, Environment and Development Economics, 13(3), 255-278. 


\section{Appendix}

We develop the simplest version of Propositions 1-4. As in the text, assume that time is continuous. Denote it variously by s and $t(\mathrm{~s} \geq t \geq 0)$. So as to keep the analysis to essentials, we avoid talking explicitly about future uncertainty; but readers may, if they so choose, interpret social well-being (expression (A.1) below) as expected social well-being, and future consumption flows and capital stocks as state contingent vectors.

Because it isn't possible to specify a final date for the economy with certainty, the future is taken to be infinitely long (expression (A.1)).

\section{A.1 Economic Perturbation as Movement Through Time: Sustainable Development}

What follows is a formal account of the theory developed in Section 10.1. Let $\underline{C}(\mathrm{~s})$ denote a vector of consumption flows at time s. $\underline{C}$ (s) includes not only standard consumption goods, but also leisure and consumption services supplied by nature. Some consumption goods are marketed, others are not. Consumption goods are indexed by $j$. Let $\underline{K}(\mathrm{~s})$ denote the quantities of a comprehensive list of capital assets at s. Those quantities are stocks. For simplicity, assume that demographic changes, movements in total factor productivity, and changes in import prices are exogenous. We will incorporate those exogenous changes into the notion of comprehensive investment by regarding time also as a capital asset. ${ }^{29}$ As in the text, all capital assets other than time are indexed by $i$.

\section{A.1.1 The Formal Analysis}

To fix ideas, assume population is constant. Let $U(\underline{C}(s), \underline{K}(s))$ be (social) felicity at s. Denote social well-being at $t$ by $V(t) . V(t)$ is a stock. For concreteness we assume that

$$
V(t)=\int\left[U(\underline{C}(s), \underline{K}(s)) e^{-\delta(s-t)}\right] d s, \quad \delta \geq 0 .
$$

$\delta$ is the felicity discount rate, which shouldn't be confused with discount rates to be applied to consumption, or investment, or income (see below). An economic forecast at $t$ is the infinite sequence $\{\underline{C}(\mathrm{~s}), \underline{K}(s)\}$ for $s \geq t$. We assume that the integral in expression (A.1) converges for the forecast. Definition 2 says that development is sustained at $t$ if

$$
d V / d t \geq 0
$$

We now prove that (A.2) is satisfied if and only if comprehensive investment at $t$ is non-negative (Proposition 3).

To save on notation, I avoid writing down an explicit dynamical model of the economy and merely note from equation (A.1) that even though sustainability has been defined for one moment of time $\mathrm{t}$ (condition (A.2)), the condition requires a forecast of the economy's future beyond $t^{30}$

29 But see Arrow et al. (2003b) for the corresponding analysis when demographic changes are endogenous to the model.

30 The sustainability criterion can be extended to cover a period of time by integrating the left hand side of expression (A.2). For details, see Dasgupta (2008b). 
That future depends on the economy's stock of assets at $t$. It also depends on the evolving structure of its technology, people's values and preferences, and institutions beyond $t$. The stock of assets at any moment $s$ in the future would be determined by the stocks at the "previous" date. ${ }^{31}$ By proceeding from moment to moment this way, the entire future course of capital stocks would be determined. In short, if $\underline{K}(t)$ were known, $\underline{K}(s)$ and $\underline{C}(s)$, and thereby $U(\underline{C}(s), \underline{K}(s))$, could be determined for all future times st t. From equation (A.1), $V(t)$ could be determined as well. Therefore we can write

$V(t)=V(\underline{K}(t), t)$.

In equation (A.3) $\mathrm{V}$ depends explicitly on t because the economy is assumed to undergo changes owing to exogenous factors.

Let $q_{j}(t)$ denote the shadow price of consumption good $j$ at $t$. Then

$$
q_{j}(t)=\partial U(\underline{C}(t), \underline{K}(t)) / \partial C_{j}(t) .
$$

But Proposition 3 says that the shadow prices we need for sustainability analysis are those for the economy's capital assets.

Let us assume without justification that $V(t)$ is differentiable..$^{32}$ Differentiating $V(t)$ with respect to t in (A.3) and using (A.2) yields the criterion for sustainable development at t:

$$
d V(t) / d t=\partial V / \partial t+{ }_{i} \Sigma\left[\left(\partial V(t) / \partial K_{i}(t)\right)\left(d K_{i}(t) / d t\right)\right] \geq 0 .
$$

As in Section 9, define

$$
p_{i}(t)=\partial V(t) / \partial K_{i}(t), \quad \text { for all } i .
$$

$p i(t)$ is the (spot) shadow price of the $i^{\text {th }}$ asset at $t$ (Definition 1 ). If $i$ is a factor of production as well as a final consumption good (e.g., a wetland), $p_{i}(t)$ reflects both. From expressions (A.1), (A.4) and (A.6), we note that the shadow price of consumption goods at all $s$ (the $\left.q_{j}(s) s\right)$ are embodied in the shadow price of capital assets at $t\left(\right.$ the $\left.p_{i}(t) s\right)$.

As in Section 9, write $I_{i}(t)=p_{i}(t)\left(d K_{i}(t) / d t\right)$ for net investment in asset $i$. Using equation (A.6) in equation (A.5) gives us

$$
d V(t) / d t=\partial V / \partial t+{ }_{i} \Sigma\left[p_{i}(t)\left(d K_{i}(t) / d t\right)\right] \geq 0,
$$

or

$$
=\partial V / \partial t+{ }_{i} \Sigma\left[I_{i}(t)\right]
$$

An easy way to interpret ? $\mathrm{V} /$ ?t is to regard time itself as a capital asset, say $\mathrm{Z}$. If $\mathrm{Z}=\mathrm{t}$, we have

$$
d \mathrm{Z} / \mathrm{dt}=1
$$

\footnotetext{
31 We qualify only because in continuous time there is no "previous" date.

32 Dasgupta (2001a: Appendix) offers the justification.
} 
With equation (A.9) defining the additional asset, ?V/?t (=?V/?Z) becomes the shadow price of time and the right hand side of equation (A.8) becomes comprehensive investment at $t$. This proves Proposition 3.

\section{A.1.2 Accounting for Population Growth}

Population is a capital asset. In macroeconomic models population growth is usually assumed to be exogenous. We make the same assumption here. Let us also assume that population cohorts are identical in their preferences and abilities. Then the size of the population, $P(t)$, is the stock of the demographic asset. It may seem intuitive that the way to tease exogenous growth in population out of $M V / M t$ is to define comprehensive wealth in per capita terms and re-express Proposition 1 accordingly. Dasgupta (2001a) showed that to be a correct move only under very special circumstances. Let us see why in general the move is illegitimate.

Write $c(t)=C(t) / P(t)$. In his classic work on optimum saving under constant population growth, Koopmans $(1965,1967)$ assumed social well-being to be the present discounted sum of each generation's average felicity, where average felicity is a function solely of average consumption. If, within each generation, consumption is equally distributed, Koopmans' $V(t)$ assumes the form (equation (12) in the text),

$$
V(t)=\int^{\infty}\left[U(c(s)) e^{-\delta(s-t)}\right] d s \quad \delta \geq 0 .
$$

Meade (1955) had however already drawn attention to a deep problem with expression (A.10): it discriminates against future people if population increases with time.

An alternative (studied in the context of optimum saving, by Meade, 1966; Mirrlees, 1967; Arrow and Kurz, 1970; Arrow et al., 2003b; and in the context of optimum saving and population by Dasgupta, 1969) is the present discounted sum of each generation's total felicity:

$$
V(t)=\int^{\infty}\left[P(s) U(c(s)) e^{-\delta(s-t)}\right] d s .
$$

Arrow et al. (2003b) showed that if expression (A.11) is used for studying sustainable development, we would need to specify the level of consumption, c, at which $U(c)=0$, which would mean that when specifying $U$ we would have only one degree of freedom (the scale of $U$ ). In the problem of optimum saving (as in Arrow and Kurz, 1970) we wouldn't be required to do that, because we are free to choose both the scale and level of $U .^{33}$

It would be convenient in preparing national accounts if the level of $U$, not just its scale, could be freely chosen. So consider the following expression for social well-being:

$$
V(t)=\int^{\infty}\left[P(s) U(c(s)) e^{-\delta(s-t)}\right] d s / \int^{\infty}\left[P(s) e^{-\delta(s-t)}\right] \mathrm{ds} .
$$

The numerator in expression (A.12) is expression (A.11), whereas the denominator is the present discounted sum of each generation's population. Let us call the ethical theory on which expression (A.12) is based, dynamic average utilitarianism.

33 In the combined problem of optimum saving and population, expression (A.11) does require of us to specify the value of $c$ at which $U(c)=0$. On this, see Meade (1955) and Dasgupta (1969). 
Notice that the denominator in expression (A.12) would play no role in policy evaluation at $t$ (questions (D) and (E); Section 11), because the denominator would simply be a scale factor attached to expression (A.11). But for sustainability analysis (questions (B) and (C); Section 10) the denominator matters, because the evaluation there is undertaken across time.

Let $k_{i}(t)=K_{i}(t) / P(t)$. Now write $\underline{k}=\left(k_{1}, k_{2}, \ldots, k_{i}, \ldots\right)$. From expression (A.12), we have

$$
V(t)=V(\underline{k}(t), P(t))
$$

Dasgupta (2001a) showed that if P grows (or declines) at a constant rate and if each of the equations that represent the economy's accumulation process can be expressed in terms solely of per capita capital stocks, then $M V(t) / M P(t)=0$. That proves Proposition 4 .

\section{A.2 Policy Evaluation}

Proposition 6 offered a well-known interpretation of comprehensive investment. To prove it, imagine that the vector of assets at $t$ is not $\underline{K}(t)$ but $\underline{K}(t)+\chi \underline{K}(t)$, where $\Delta$ is an operator denoting a small difference. For simplicity of exposition, suppose (a) there is a single consumption good, (b) population is constant, and (c) felicity depends solely on consumption. In the obvious notation, we then have

$$
V(\underline{K}(t)+\Delta \underline{K}(t))=\int^{\infty}\left[U^{\prime}(C(s)) \Delta C(s) e^{-\delta(s-t)}\right] d s .
$$

Now imagine that at $t$ there a small increase in investment, but only for a brief moment, $\Delta t$. We write the change in the vector of capital assets at $t+\Delta t$ consequent upon the brief increase in investment as $\Delta \underline{K}(t)$. So $\underline{K}(t+\Delta t)+\Delta \underline{K}(t))$ is the resulting vector of capital assets at $t+\Delta t$. Let $\Delta t$ tend to zero. Equation (A.14) then yields Proposition 6.

Earlier we observed that $\delta$ in expression (A.1) is the felicity discount rate. (In the literature on environmental and resource economics $\delta$ is frequently called the "pure rate of time preference".) It is the discount rate to be used if a policy reform (or a project) is described in terms of the changes it brings about to felicities over time. However, policy reforms are typically characterized in terms of the perturbations they cause to commodity flows (e.g. consumption flows); which is why it has been customary in social cost-benefit analysis to regard consumption as the numeraire. Equation (A.14) says that, viewed from $t$, the social discount factor at date $s$ is $U N(C(s)) e-{ }^{\delta}(s-t)$. Let $p(s)$ be the social discount rate at s (the percentage rate of decline of the consumption discount factor). An easy calculation shows that

$$
\rho(s)=-\left[\left(C(s) U^{\prime \prime}(C(s)) / U^{\prime}(C(s))\right][d C(s) / d s] / C(\mathrm{~s})+\delta .\right.
$$

But $-\left(C(s) U^{\prime \prime}(C(s)) / U^{\prime}(C(s))\right.$ is the elasticity of marginal felicity. If we denote that by a(C(s)), equation (A.15) reduces to the familiar form

$$
\rho(s)=\alpha(C(s))[d C(s) / d s] / C(s)+\delta .
$$

If equality in consumption is valued, then $U^{\prime \prime}(C(s))<0$; but that means $\alpha(C(s))>0$. 
It has been common to assume that $\alpha$ is constant. To the best of my knowledge the whole literature on the economics of climate change has been based on that assumption. Equation (A.16) says that even if $\alpha(C(s))$ is taken to be a constant, $p(s)$ would be constant only along steady states. The equation also says that $p(s)$ is negative if consumption is expected to decline at s (Dasgupta, 2001a). As we noted in Section 11.3, this has far reaching consequences for the choice of social discount rates when the future is uncertain. 
TABLE

Table 1: The Progress of Poor Nations

\begin{tabular}{|l|c|c|c|c|c|c|}
\hline Country/Region & & \multicolumn{4}{|c|}{ \% Annual growth rate 1970-2000 } & \\
\hline & $\begin{array}{c}\text { I/Y* } \\
\text { (percentage) }\end{array}$ & $\begin{array}{c}\text { Population } \\
\text { (per head) }\end{array}$ & TFP & $\begin{array}{c}\text { Comprehensive } \\
\text { Wealth } \\
\text { (per head) }\end{array}$ & $\begin{array}{c}\text { GDP } \\
\text { per head })\end{array}$ & HDI $^{\dagger \dagger}$ \\
\hline Sub-Saharan Africa & -2.1 & 2.7 & 0.1 & -2.81 & -0.1 & + \\
\hline Bangladesh & 7.1 & 2.2 & 0.7 & -0.79 & 1.9 & + \\
\hline India & 9.5 & 2.0 & 0.6 & -0.45 & 3.0 & + \\
\hline Nepal & 13.3 & 2.2 & 0.5 & -0.37 & 1.9 & + \\
\hline Pakistan & 8.8 & 2.7 & 0.4 & -1.42 & 2.2 & + \\
\hline China & 22.7 & 1.4 & 3.6 & 4.47 & 7.8 & + \\
\hline
\end{tabular}

* comprehensive investment as a share of GDP (average over 1970-2000).

+ total factor productivity.

${ }^{+\dagger}$ change in HDI between 1970 and 2000.

Adapted from K. J. Arrow, P. Dasgupta, L. Goulder, G. Daily, P. R. Ehrlich, G. M. Heal, S. Levin, K.-G. Maler, S. Schneider, D. A. Starrett, and B. Walker, “Are We Consuming Too Much?”, Journal of Economic Perspectives, 2004, Vol. 18, No. 3, pp. 147-172. 


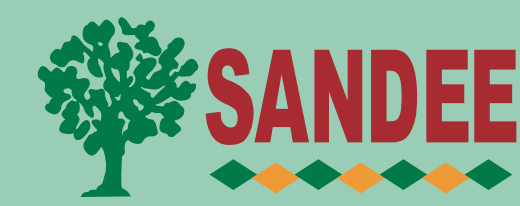

South Asian Network for Development and Environmental Economics

\section{SANDEE}

PO Box 8975 EPC 1056

Kathmandu, Nepal

Tel: 977-1-552 8761

Fax: 977-1-553 6786

E-mail: info@sandeeonline.org

Website: www.sandeeonline.org

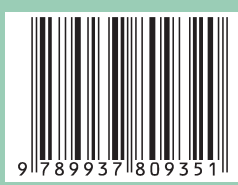

\section{SANDEE Sponsors}

\section{IUCN}

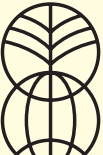

NORAD

\section{纱 Sida}

Swedish International Development Cooperation Agency

\section{IDRC * CRDI}

